\title{
Testing of a single grain OSL chronology across the Middle to Upper Palaeolithic transition at Les Cottés (France)
}

\author{
Zenobia Jacobs ${ }^{\text {a, }}{ }^{*}$, Bo Li a , Nathan Jankowski ${ }^{\text {a }}$, Marie Soressi ${ }^{\text {b, c }}$ \\ ${ }^{a}$ Centre for Archaeological Science, School of Earth and Environmental Sciences, University of Wollongong, Wollongong, 2522, Australia \\ ${ }^{\mathrm{b}}$ Faculty of Archaeology, Leiden University, PO Box 9514, 2300 RA, Leiden, The Netherlands \\ ${ }^{\mathrm{c}}$ Department of Human Evolution, Max Planck Institute for Evolutionary Anthropology, Deutscher Platz 6, D-04103, Leipzig, Germany
}

\section{A R T I C L E I N F O}

\section{Article history:}

Received 8 September 2014

Received in revised form

15 November 2014

Accepted 18 November 2014

Available online 26 November 2014

\section{Keywords:}

OSL dating

Radiocarbon dating

Upper Palaeolithic

Aurignacian

Châtelperronian

Middle Palaeolithic

Mousterian

France

\begin{abstract}
A B S T R A C T
The timing of the Middle Palaeolithic to Upper Palaeolithic transition in France is important to help understand when, where and how Neanderthals have been replaced by Homo sapiens. Radiocarbon dating has been the dating workhorse in constructing the chronological framework pertinent to these questions. In this study, we are testing whether single grain OSL dating has the accuracy and precision to be useful as a complementary dating method. The site of Les Cottés provides an ideal testing ground because of its stratigraphic integrity and reliable radiocarbon chronology. We applied single grain OSL dating of quartz to 19 samples and multi-aliquot MET-pIRIR dating of potassium-rich feldspar grains to 5 samples to explicitly test assumptions of pre-depositional resetting of the OSL signal and postdepositional exposure to variable beta dose rates. The good agreement between the single grain OSL and the multi-aliquot MET pIRIR ages suggest that the optical signals of both quartz and feldspar grains were reset prior to deposition and that much of the extra scatter observed in the equivalent dose distribution of quartz grains are likely due to the small-scale differences in beta dose delivered to individual grains. Both the quartz OSL and feldspar MET-pIRIR ages show great consistency with the ${ }^{14} \mathrm{C}$ ages on bone collected from the same units. This gives confidence in the measurement and analytical approaches used to derive both the equivalent dose and dose rate, the numerator and denominator, respectively, of the luminescence age equation. These results suggest that a systematic and detailed single grain OSL dating study can have the accuracy and precision that is necessary to play a powerful role in the dating of the Middle and Upper Palaeolithic transition and other questions of importance in this time range and geographical area.
\end{abstract}

๑) 2014 Elsevier Ltd. All rights reserved.

\section{Introduction}

Radiocarbon $\left({ }^{14} \mathrm{C}\right)$ dating is playing a crucial role is estimating the timing of the transition from the Middle Palaeolithic (MP) to the Upper Palaeolithic (UP) in Europe (e.g., Benazzi et al., 2007; Pinhasi et al., 2011; Douka et al., 2014; Higham et al., 2014; Wood et al., 2013). In doing so, it contributes towards an improved understanding of the nature of the transition, the process of Neanderthal extinction, and the peopling of Europe by early anatomically modern humans. The application of ${ }^{14} \mathrm{C}$ dating plays a pivotal role in addressing key questions that include, amongst many others, whether modern humans have abruptly replaced Neanderthals or

\footnotetext{
* Corresponding author.

E-mail address: zenobia@uow.edu.au (Z. Jacobs).
}

not, and whether the two human species may have entirely independent cultural histories, or whether some interaction between the two species may have resulted in cultural diffusion. Although dating itself cannot answer these questions, it is undeniable that a reliable chronological framework for archaeological industries such as the Aurignacian and the Châtelperronian is paramount in our quest to answer these questions.

Over the past two decades significant advances have been made in both ${ }^{14} \mathrm{C}$ dating of charcoal (e.g., Bird et al., 1999), shell (e.g., Douka et al., 2010) and bone (e.g., Higham et al., 2006) and in optically stimulated luminescence (OSL) dating of sedimentary quartz (e.g., Murray and Wintle, 2000; Jacobs and Roberts, 2007) and feldspar mineral grains (Li and Li, 2011; Buylaert et al., 2012). When applying these two methods to Palaeolithic or Stone Age sites, ${ }^{14} \mathrm{C}$ dating is restricted to sites younger than its effective upper limit of $\sim 50 \mathrm{ka}$, and OSL dating is more commonly applied to sites 
older than $50 \mathrm{ka}$ (i.e., where ${ }^{14} \mathrm{C}$ dating cannot be used). Radiocarbon dating is almost always preferred for sites $<50$ ka because of the much higher precision that can be obtained, and because the dated materials (i.e., bone, charcoal, shell) are more closely associated with the dating target event (i.e., occupation). Thermoluminescence $(\mathrm{TL})$ dating of burnt flint that also directly date the target event is often applied in European contexts and across this important time period (e.g., Richter et al., 2009). In OSL dating of sediments we have to assume and demonstrate that sediment deposition was pene-contemporaneous with occupation of the site. Radiocarbon dating, therefore, allows construction of more finely resolved chronologies to match the highly resolved archaeological industries, many of relatively short duration, of the European Upper Palaeolithic (UP), in particular.

A major dilemma, however, has been that the events of interest all occurred very close to the upper limit of the ${ }^{14} \mathrm{C}$ technique. The ${ }^{14} \mathrm{C}$ ages of older samples are particularly affected by younger contaminants. For example, only $0.5 \%$ modern contamination of a sample that dates to $40 \mathrm{ka} \mathrm{BP}$, will result in an underestimation of $\sim 4.4 \mathrm{ka}$ and, thus, a measured age of $35.6 \mathrm{ka}$ BP (Higham, 2011), or $1 \%$ modern contamination of a sample $>60 \mathrm{ka}$ old, will result in a measured age of $\sim 37 \mathrm{ka} \mathrm{BP}$ (Wood et al., 2012). A swath of recent ${ }^{14} \mathrm{C}$ dating studies have confirmed how earlier ${ }^{14} \mathrm{C}$ ages produced on charcoal and bone from sites associated with the MP/UP transition have, in many cases, been underestimations because of small-scale post-depositional contamination by younger carbon that was not removed adequately during the laboratory pretreatment of the samples (e.g., Mellars, 2006; Higham et al., 2010, 2011, 2012; Talamo et al., 2012; Wood et al., 2013). Application of newgeneration pretreatment techniques, such as acid-base wet oxidation and stepped-combustion (ABOX-SC) procedures for charcoal (Bird et al., 1999), molecular ultrafiltration procedures for bone collagen (Higham et al., 2006) and X-ray diffraction and density separation procedures for shell (Douka et al., 2010), have been pushing back the ages for this critical period within the European Palaeolithic. A remaining common concern, however, is the lack of an internal test that can provide $100 \%$ assurance that even the most advanced pretreatment procedures used in ${ }^{14} \mathrm{C}$ dating are sufficient to decontaminate every sample measured. Although many convincing examples exist that demonstrate the veracity of these new-generation pretreatment techniques (e.g., Wood et al., 2012), it is still common to accept that the oldest ${ }^{14} \mathrm{C}$ ages among a distribution of ages from the same unit/layer are the closest to the true age of the sample (Higham, 2011), and correspondence with ages produced with independent dating methods is also used (Turney et al., 2001; De Torres et al., 2010; Wood et al., 2012).

In this study, we present the results of a single grain OSL and multiple aliquot multi-elevated-temperature post-IR IRSL (METpIRIR) dating study of sediments associated with the MP to UP transition at Les Cottés, France. This site has been previously dated by ${ }^{14} \mathrm{C}$ dating of bone samples that were pretreated using the ultrafiltration method and measured at two different AMS facilities (Talamo et al., 2012). The aim of this study is, thus, to test the accuracy of the single grain OSL and MET-pIRIR ages against the ${ }^{14} \mathrm{C}$ ages for that part of the chronology where the ${ }^{14} \mathrm{C}$ ages are considered to be secure (e.g., the Early and Proto-Aurignacian). If consistency can be demonstrated, then the OSL ages can be used, in turn, to test the ${ }^{14} \mathrm{C}$ chronology for that part of the sequence where the latter's accuracy become more ambiguous (e.g., the Mousterian). Les Cottés provides an excellent testing ground since it is one of only a few sites that contain a complete sequence of the cultural phases that make up the MP to UP transition in France. Furthermore, many of the cultural phases are separated by sedimentary layers that contain little or no archaeological remains, so post-depositional mixing between the different cultural phases can be ruled out.

\section{Site setting, stratigraphy and archaeological context}

Les Cottés (Vienne, France) is located on the northern foot of the plateau separating the Parisian basin and the Aquitaine basin in west-central France (Fig. 1a). The site is positioned at the entrance of a cave cavity inside a Jurassic limestone cliff that is $\sim 9 \mathrm{~m}$ high, overlooking the left bank of the Gartempe river. The cave itself is $7 \mathrm{~m}$ above the level of the river, which is currently $150 \mathrm{~m}$ east of the site.

The deposits inside the cave were excavated in 1881 by de Rochebrune, but all subsequent excavations, including those by Pradel in the 1950s and the new investigations since 2006 by Soressi, have focussed on the deposits at the mouth of the cave and those immediately outside the cave (Fig. 1b) (Roussel and Soressi, 2013).

The archaeological materials are found in a sandy-clay matrix, together with large quantities of centimetre- to decimetre-size limestone clasts of limestone. The sediments are thought to be derived from lacustrine and aeolian deposits that are present on the plateau and slopes surrounding the site. Slope run-off as well as disintegration of the limestone cliff appears to be the most likely process of site formation, but a detailed geological investigation is still underway. The sediments are very similar in all stratigraphic units (see below), with some having slightly higher clay content than others. Some large blocks of limestone can also be found within the deposit. The entire deposit outside the cave dips at $\sim 10^{\circ}$ in the direction of the river, with the thickest part of the deposits being those closest to the cave walls. So, the maximum separation of the different archaeological industries can be found in the deposits closest to the cave mouth.

The current excavation team has divided the sedimentary deposits into 8 broad stratigraphic units, termed US01-US08, each also containing smaller sub-divisions. These can be correlated with the different archaeological industries that were first described by Pradel (1961), and further defined by Soressi et al. (2010) and Roussel and Soressi (2013). US08 relates to the Mousterian, for which there are currently too few lithics to be assigned to a particular Mousterian variant (e.g., typical Mousterian, Mousterian of Acheulian Tradition etc.). US06 represents the Châtelperronian (CP) that contains 'Les Cottés points' described by Pradel (1963) as characteristic of the 'evolved' CP. The lower part of US04 (US04.4) contains the Proto-Aurignacian (PA) and the upper part of US04 (04.1 and 04.2) contains the first expression of the Early Aurignacian (EA) at the site. Further evidence for the EA is also found in US02 and is referred to, at this site, as the Upper EA (UEA). The remaining and inter-stratified units (US 01, 03, 05 and 07) are virtually archaeologically sterile (see Table 2 in Talamo et al., 2012). These archaeologically sterile units clearly separate the major archaeological industries. For example, the Mousterian in US08, at the base of the current excavation, is separated from the CP (US06) by a $\sim-15 \mathrm{~cm}$ thick sterile layer (US07), and this CP unit is separated from the PA (US04lower) by a $\sim 10 \mathrm{~cm}$ thick sterile layer (US05). A 40 cm thick sterile clay layer (US03) clearly separates the EA (US04upper) from the UEA (US02). Because of the sloping deposits and the sedimentary processes at play, the site is not a complete 'horizontal layer cake' and the separation is clearer in some parts than in others. Fig. 1c shows a photograph of all the exposed section walls and Fig. 2 shows a close-up photograph and schematic view of the stratigraphy of the three parts of the section from which OSL samples were collected.

\section{Optical dating}

Optical dating provides a means of determining burial ages for sediments (Huntley et al., 1985; Aitken, 1998; Jacobs and Roberts, 


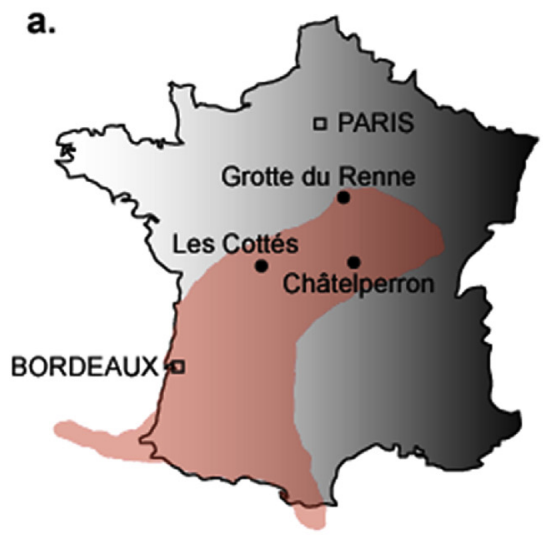

b.

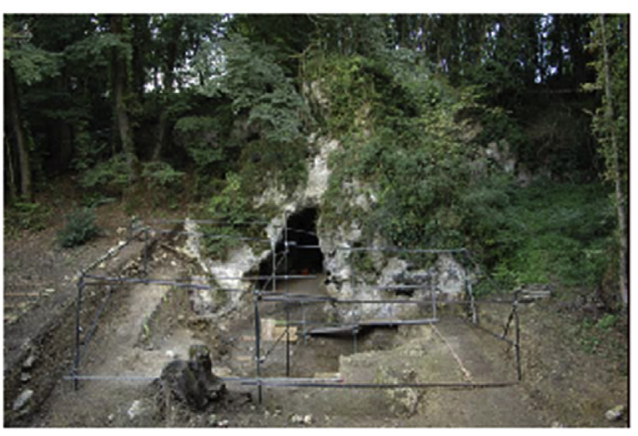

c.

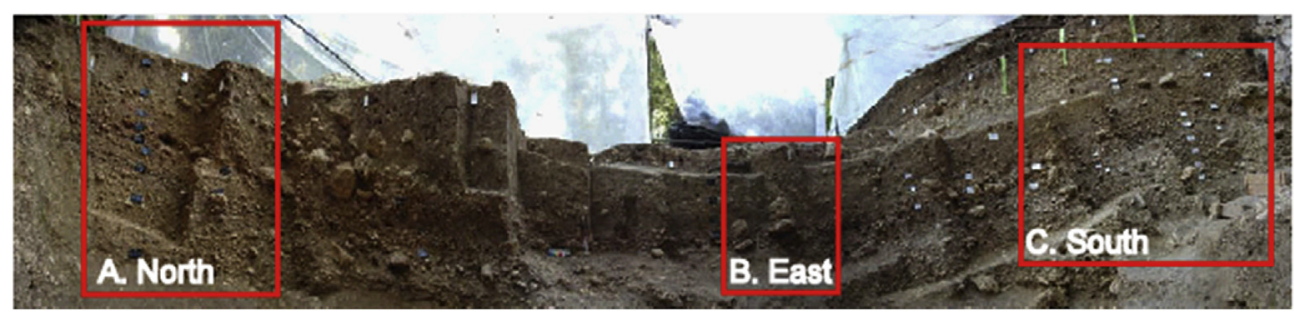

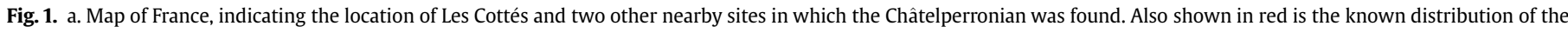

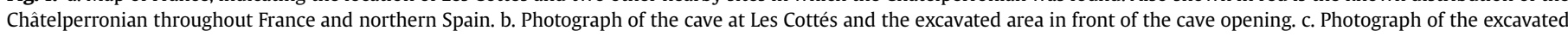

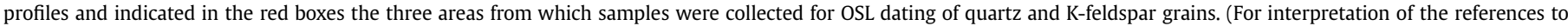
colour in this figure legend, the reader is referred to the web version of this article.)

2007; Wintle, 2008). The method is based on the increase in the number of trapped electrons in mineral grains, such as quartz and feldspar, that increases steadily over time after burial, in response to the energy supplied by background levels of ionising radiation from environmental sources. The time elapsed since sediments were last exposed to sufficient heat or sunlight to empty the relevant electron traps can be estimated from measurements of the OSL or infrared stimulated luminescence (IRSL) signals to obtain an estimate of the equivalent dose $\left(D_{e}\right)$, together with determinations of the radioactivity of the sample and the material surrounding it to a distance of $\sim 40 \mathrm{~cm}$ to obtain an estimate of the dose rate $\left(D_{r}\right)$. The $D_{e}$ represents the radiation dose to which sedimentary grains have been exposed in their burial environment. The $D_{r}$ represents the rate of exposure of these grains to ionising radiation over the entire period of burial; this radiation is mostly derived from the radioactive decay of ${ }^{238} \mathrm{U},{ }^{235} \mathrm{U},{ }^{232} \mathrm{Th}$ (and their daughter products) and ${ }^{40} \mathrm{~K}$, with lesser contributions from cosmic rays and from radioactive inclusions internal to the dated mineral grains (of which ${ }^{40} \mathrm{~K}$ and ${ }^{87} \mathrm{Rb}$ make a significant contribution to sand-sized K-feldspar grains). The burial age of grains that were well-bleached at the time of deposition can then be calculated by dividing the estimated $D_{e}$ by the estimated $D_{r}$ for the entire period of burial.

In this study, we estimated the OSL $D_{e}$ values for all our samples using individual sand-sized grains of quartz. One of the most important advantages of single grain measurements of quartz is the ability to identify and eliminate individual grains that exhibit aberrant luminescence characteristics, as these can lead to erroneous $D_{e}$ estimates when grains are combined on a multi-grain aliquot (Jacobs et al., 2006; Jacobs and Roberts, 2007). In addition to the removal of grains with aberrant luminescence behaviours, analysis of individual grains of quartz has further benefits in archaeological contexts where: 1) post-depositional disturbances (Jacobs et al., 2006, 2008b; Feathers et al., 2006, 2010; David et al., 2007), and 2) the possibility of roof spall contamination and other forms of non-homogeneous bleaching (Roberts et al., 1998, 1999; Jacobs et al., 2011) are of concern (Jacobs and Roberts, 2007). The archaeological sediments at Les Cottés show little potential for mixing because of the clear separation between archaeological units and sedimentary units that are archaeologically sterile. Roof spall contamination is also not a major concern. We dissolved numerous chunks of limestone found within our samples and established that the limestone is quite pure with no detectable sand-sized grains of quartz or feldspar. Partial resetting of the OSL signal remains a possibility because of the dominant site formation process (i.e., slope run-off). A potential weakness of single grain measurements, in a context like that presented at Les Cottés, is the possible complications of beta microdosimetry - that is, the smallscale differences in the beta dose rate delivered to individual grains. Each individual grain is influenced by the radioactivity of any particle present within a surrounding radius of $2-3 \mathrm{~mm}$. As the beta dose rate for a sample is based on an average estimate and not a grain-specific estimate, the ubiquitous occurrence of small and large limestone pieces throughout the deposits may, thus, lead to greater-than-expected scatter in the single grain $D_{e}$ estimates (Murray and Roberts, 1997).

To check the reliability of our single grain measurements, we also estimated the IRSL $D_{e}$ values for a sub-set of our samples using multiple aliquots of sand-sized grains of K-feldspar. K-feldspar grains are much less affected by differences in the external beta dose rate as they have a much greater contribution to the dose rate derived from radioactive ${ }^{40} \mathrm{~K},{ }^{87} \mathrm{Rb}$, as well as uranium and thorium, occurring within the mineral grains. This internal component of the dose rate is not affected by the inhomogeneous distribution of radioactivity external to the grains, thus reducing the effect that small-scale variations in the external beta dose rate may have on the spread in $D_{e}$ values. Additionally, the effect will be averaged due to the use of large numbers of grains on each aliquot. Feldspars, however, have long been known to suffer from a malign physical 
Table 1

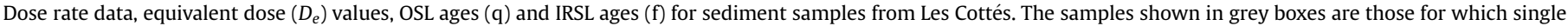
grain quartz and multiple aliquot K-feldspar grains were measured.

\begin{tabular}{|c|c|c|c|c|c|c|c|c|c|}
\hline Sample code & $\begin{array}{l}\text { Field moisture } \\
\text { content (\%) }\end{array}$ & Beta $^{b}$ & $\begin{array}{l}\text { External dose } \\
\text { rates }(\mathrm{Gy} / \mathrm{ka}) \\
\text { Gamma }\end{array}$ & Cosmic & $\begin{array}{l}\text { Total dose } \\
\text { rate }(\mathrm{Gy} / \mathrm{ka})\end{array}$ & $D_{e}(\mathrm{~Gy})^{\mathrm{a}}$ & $\begin{array}{l}\text { Number } \\
\text { of grain }\end{array}$ & $\begin{array}{l}\text { Over-dispersion } \\
(\%)\end{array}$ & $\begin{array}{l}\text { Optical } \\
\text { age (ka) }\end{array}$ \\
\hline \multicolumn{10}{|l|}{ US01 - Sterile } \\
\hline LC10-1 (q) & 6 & $1.00 \pm 0.05$ & $0.53 \pm 0.02$ & 0.14 & $1.72 \pm 0.06$ & $62.8 \pm 1.3$ & $182 / 1000$ & $22 \pm 2$ & $36.6 \pm 1.6$ \\
\hline $\mathrm{LC} 10-2(\mathrm{q})$ & 6 & $1.11 \pm 0.05$ & $0.89 \pm 0.04$ & 0.11 & $2.15 \pm 0.07$ & $74.3 \pm 1.6$ & $162 / 1000$ & $24 \pm 2$ & $34.5 \pm 1.5$ \\
\hline \multicolumn{10}{|c|}{ US02 - Upper Early Aurignacian } \\
\hline $\begin{array}{l}\mathrm{LC} 10-3(\mathrm{q}) \\
\text { (f) }\end{array}$ & 8 & $\begin{array}{l}1.25 \pm 0.06 \\
1.32 \pm 0.06\end{array}$ & $1.05 \pm 0.04$ & 0.11 & $\begin{array}{l}2.45 \pm 0.08 \\
2.96 \pm 0.09\end{array}$ & $\begin{array}{l}88.7 \pm 1.6 \\
101 \pm 7\end{array}$ & $176 / 1000$ & $23 \pm 2$ & $\begin{array}{l}36.2 \pm 1.8 \\
34.1 \pm 2.7\end{array}$ \\
\hline LC10-4 (q) & 16 & $1.22 \pm 0.07$ & $0.96 \pm 0.05$ & 0.10 & $2.31 \pm 0.09$ & $85.1 \pm 1.9$ & $111 / 900$ & $20 \pm 2$ & $36.9 \pm 1.8$ \\
\hline LC10-5 (q) & 15 & $1.22 \pm 0.07$ & $0.99 \pm 0.05$ & 0.17 & $2.40 \pm 0.09$ & $94.1 \pm 1.6$ & $178 / 1000$ & $27 \pm 2$ & $39.1 \pm 1.8$ \\
\hline \multicolumn{10}{|l|}{ US03 - Sterile } \\
\hline LC10-6 (q) & 15 & $1.14 \pm 0.07$ & $0.92 \pm 0.05$ & 0.16 & $2.23 \pm 0.08$ & $93.3 \pm 1.3$ & $411 / 2000$ & $23 \pm 1$ & $41.9 \pm 1.9$ \\
\hline $\begin{array}{l}\text { LC10-7 (q) } \\
\text { (f) }\end{array}$ & 20 & $\begin{array}{l}1.17 \pm 0.08 \\
1.24 \pm 0.08\end{array}$ & $0.94 \pm 0.06$ & 0.16 & $\begin{array}{l}2.27 \pm 0.10 \\
2.79 \pm 0.11\end{array}$ & $\begin{array}{l}89.7 \pm 2.4 \\
111 \pm 7\end{array}$ & $123 / 1000$ & $23 \pm 1$ & $\begin{array}{l}39.5 \pm 2.1 \\
39.8 \pm 3.0\end{array}$ \\
\hline \multicolumn{10}{|c|}{ US04 upper - Early Aurignacian } \\
\hline LC10-8 (q) & 19 & $1.16 \pm 0.08$ & $0.65 \pm 0.04$ & 0.15 & $1.96 \pm 0.09$ & $77.3 \pm 2.2$ & $108 / 900$ & $25 \pm 2$ & $39.4 \pm 2.2$ \\
\hline LC10-9 (q) & 16 & $0.93 \pm 0.06$ & $0.62 \pm 0.03$ & 0.12 & $1.68 \pm 0.07$ & $69.6 \pm 1.7$ & $96 / 1000$ & $22 \pm 2$ & $41.3 \pm 2.1$ \\
\hline \multicolumn{10}{|c|}{ US04 lower - Proto-Aurignacian } \\
\hline $\begin{array}{l}\text { LC10-11(q) } \\
\text { (f) }\end{array}$ & 16 & $\begin{array}{l}1.15 \pm 0.07 \\
1.22 \pm 0.07\end{array}$ & $0.59 \pm 0.03$ & 0.12 & $\begin{array}{l}1.87 \pm 0.08 \\
2.38 \pm 0.09\end{array}$ & $\begin{array}{l}76.0 \pm 1.2 \\
98 \pm 5\end{array}$ & $296 / 2000$ & $25 \pm 1$ & $\begin{array}{l}40.7 \pm 2.0 \\
41.1 \pm 2.7\end{array}$ \\
\hline $\begin{array}{l}\text { LC11-3 (q) } \\
\text { US05 - Steril }\end{array}$ & 9 & $0.97 \pm 0.05$ & $0.68 \pm 0.03$ & 0.12 & $1.78 \pm 0.06$ & $71.1 \pm 1.7$ & $125 / 1000$ & $19 \pm 2$ & $39.9 \pm 1.8$ \\
\hline LC11-1 (q) & 8 & $0.90 \pm 0.05$ & $0.68 \pm 0.03$ & 0.11 & $1.71 \pm 0.06$ & $72.6 \pm 2.1$ & $75 / 1000$ & $16 \pm 3$ & $42.4 \pm 2.1$ \\
\hline \multicolumn{10}{|c|}{ US06 - Châtelperronian } \\
\hline LC10-13(q) & 11 & $0.99 \pm 0.05$ & $0.60 \pm 0.03$ & 0.10 & $1.72 \pm 0.06$ & $65.9 \pm 1.4$ & $267 / 1900$ & $30 \pm 2$ & $38.4 \pm 1.8$ \\
\hline LC10-15(q) & 12 & $1.03 \pm 0.06$ & $0.49 \pm 0.02$ & 0.08 & $1.63 \pm 0.06$ & $70.5 \pm 2.2$ & $70 / 1000$ & $32 \pm 4$ & $43.3 \pm 2.3$ \\
\hline $\mathrm{LC} 11-2(\mathrm{q})$ & 11 & $0.94 \pm 0.05$ & $0.71 \pm 0.03$ & 0.09 & $1.77 \pm 0.06$ & $76.1 \pm 2.0$ & $128 / 1000$ & $26 \pm 2$ & $43.1 \pm 2.1$ \\
\hline \multicolumn{10}{|l|}{ US07 - Sterile } \\
\hline $\begin{array}{l}\text { LC10-16(q) } \\
\text { (f) }\end{array}$ & 13 & $\begin{array}{l}1.01 \pm 0.06 \\
1.07 \pm 0.06\end{array}$ & $0.48 \pm 0.02$ & 0.07 & $\begin{array}{l}1.59 \pm 0.06 \\
2.10 \pm 0.07\end{array}$ & $\begin{array}{l}75.3 \pm 1.5 \\
90 \pm 8\end{array}$ & $174 / 1000$ & $21 \pm 2$ & $\begin{array}{l}47.3 \pm 2.3 \\
42.9 \pm 4.2\end{array}$ \\
\hline \multicolumn{10}{|c|}{ US08 - Mousterian } \\
\hline LC10-17(q) & 16 & $1.01 \pm 0.06$ & $0.55 \pm 0.03$ & 0.07 & $1.66 \pm 0.07$ & $84.5 \pm 1.7$ & $198 / 1000$ & $23 \pm 2$ & $50.7 \pm 2.5$ \\
\hline LC10-18(q) & 8 & $1.10 \pm 0.06$ & $0.52 \pm 0.02$ & 0.06 & $1.71 \pm 0.06$ & $87.2 \pm 1.9$ & $157 / 1000$ & $28 \pm 2$ & $50.9 \pm 2.4$ \\
\hline $\begin{array}{l}\text { LC10-19(q) } \\
\text { (f) }\end{array}$ & 11 & $\begin{array}{l}1.05 \pm 0.06 \\
1.11 \pm 0.06\end{array}$ & $0.73 \pm 0.03$ & 0.06 & $\begin{array}{l}1.87 \pm 0.07 \\
2.37 \pm 0.08\end{array}$ & $\begin{array}{l}98.2 \pm 2.7 \\
116 \pm 5\end{array}$ & $104 / 1000$ & $22 \pm 2$ & $\begin{array}{l}52.7 \pm 2.6 \\
48.9 \pm 2.8\end{array}$ \\
\hline
\end{tabular}

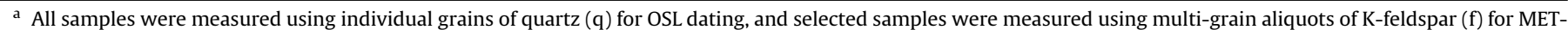
pIRIR dating.

b All multi-grain aliquot MET-pIRIR measurements were made on 90-125 $\mu$ m diameter grains, and all single-grain quartz OSL measurements were made on 180-212 $\mu$ m diameter grains. The beta dose rates have been adjusted accordingly.

c All feldspar dose rates include a $0.48 \pm 0.04 \mathrm{~Gy} / \mathrm{ka}$ internal dose rate contribution.

d All feldspar $D_{e}$ values are based on the mean value obtained for the measurements made at a stimulation temperature of $250{ }^{\circ} \mathrm{C}$.

property called 'anomalous' fading, which is the leakage of electrons from traps at a much faster rate than would be expected from kinetic considerations (Wintle, 1973). If this fading is not corrected, it often leads to a significant underestimation of the age of a sample. Recent progress in understanding anomalous fading in feldspar has raised the prospect of isolating a non-fading IRSL component, or one less prone to fading; see Li et al. (2014) for a current overview of the methods. This can be achieved by first bleaching the feldspar grains using IR photons at $50{ }^{\circ} \mathrm{C}$ and then measuring the post-IR IRSL (pIRIR) signal at an elevated temperature $\left(>200{ }^{\circ} \mathrm{C}\right)$ (Thomsen et al., 2008; Buylaert et al., 2009, 2012; Thiel et al., 2011), or by stimulating the feldspar grains with IR photons at successively higher temperatures from 50 to $300{ }^{\circ} \mathrm{C}$ using the so-called multiple-elevated-temperature (MET) pIRIR procedure of $\mathrm{Li}$ and $\mathrm{Li}$ (2011, 2012). We chose to use the MET-pIRIR method (see discussion below). The major drawback of pIRIR signals is that they are less sensitive to sunlight compared to the conventional IRSL signal or the OSL signal in quartz, and a residual signal is often observed even after an extended bleach (e.g., Li et al., 2013). Given the different signal sensitivities to light exposure, should the quartz and feldspar ages agree then adequate bleaching of the grains during sediment transport prior to burial is demonstrated. So, by using this multiple $D_{e}$ estimation approach, we should be able to satisfy most of our concerns regarding pre-depositional bleaching and post-depositional beta microdosimetry.

\section{Sample collection}

Nineteen sediment samples were collected for optical dating from each of the major stratigraphic units, including the archaeologically sterile layers. All samples were collected at night using a red light torch for illumination and an auger to extract the sediments from the cleaned section walls. Additional sample material was collected during the day from each sample location for laboratory-based measurements of radioactivity and field moisture content. Fig. 2 shows the positions of all 19 samples in their sedimentary, stratigraphic and archaeological contexts and the same data are presented in Table S1.

Samples were collected from three different areas of the excavation, along the north, east and south walls where the different archaeological industries are best represented and most clearly separated. The red squares in Fig. 1c indicate the relative positions of the sampled profiles. Along the north wall, in squares R4 and R5 (Fig. 2A), we collected 6 samples from the thickest part of the CP (US06), the sterile layer overlying the CP (US05), the PA (US04 lower) and the EA (US04 upper). Along the east wall (Fig. 2B), into square X8, we collected 4 samples: one from the EA (US04 upper), two from the thick sterile clay-layer (US03) and one sample from the UEA (US02). This profile gave us the clearest, most horizontal representation of the upper part of the archaeological sequence, but the lower part is not yet revealed here. Along the south wall 
Table 2

Summary of all ages obtained from Les Cottés. The OSL and pIRIR ages are the same as those presented in Table 1. Also provided are the $P$-values for the OSL ages within each stratigraphic unit (US) to check whether the individual ages in each unit is statistically consistent to allow calculation of a weighted mean OSL age. The ${ }^{14} \mathrm{C}$ age ranges are based on the lowest and highest calibrated ages for all samples in a unit (see Table S5). The age ranges provided in italics do not include the ages identified in Talamo et al. (2012) as outliers.

\begin{tabular}{|c|c|c|c|c|c|}
\hline $\begin{array}{l}\text { Sample } \\
\text { name }\end{array}$ & $\begin{array}{l}\text { OSL } \\
\text { age (ka) }\end{array}$ & $P$-value & $\begin{array}{l}\text { Weighted } \\
\text { mean OSL } \\
\text { age (ka) }\end{array}$ & $\begin{array}{l}\text { pIRIR } \\
\text { age (ka) }\end{array}$ & $\begin{array}{l}{ }^{14} \mathrm{C} \text { age range } \\
(68 \% \mathrm{CI}) \\
(\mathrm{ka} \text { cal } \mathrm{BP})\end{array}$ \\
\hline \multicolumn{6}{|c|}{ US01 - Sterile } \\
\hline LC10-1 & $36.6 \pm 1.6$ & \multirow[t]{2}{*}{0.16} & \multirow{2}{*}{$35.5 \pm 1.5$} & \multirow[t]{2}{*}{-} & \multirow[t]{2}{*}{-} \\
\hline LC10-2 & $34.5 \pm 1.5$ & & & & \\
\hline \multicolumn{6}{|c|}{ US02 - Upper Early Aurignacian } \\
\hline LC10-3 & $36.2 \pm 1.8$ & \multirow[t]{3}{*}{0.21} & \multirow[t]{3}{*}{$37.2 \pm 1.5$} & \multirow[t]{3}{*}{$34.1 \pm 2.7$} & \multirow[t]{3}{*}{$36.7-35.3$} \\
\hline LC10-4 & $36.9 \pm 1.8$ & & & & \\
\hline LC10-5 & $39.7 \pm 2.7$ & & & & \\
\hline \multicolumn{6}{|c|}{ US03 - Sterile } \\
\hline LC10-6 & $41.9 \pm 1.9$ & \multirow[t]{2}{*}{0.28} & \multirow[t]{2}{*}{$41.0 \pm 2.0$} & & \multirow[t]{2}{*}{-} \\
\hline LC10-7 & $39.5 \pm 2.1$ & & & $39.8 \pm 3.0$ & \\
\hline \multicolumn{6}{|c|}{ US04 upper - Early Aurignacian } \\
\hline LC10-8 & $39.7 \pm 3.1$ & \multirow[t]{2}{*}{0.56} & \multirow[t]{2}{*}{$40.5 \pm 2.1$} & \multirow[t]{2}{*}{-} & \multirow{2}{*}{$\begin{array}{l}39.3-37.0 \\
(38.6-37.0)\end{array}$} \\
\hline LC10-9 & $41.3 \pm 2.1$ & & & & \\
\hline \multicolumn{6}{|c|}{ US04 lower - Proto Aurignacian } \\
\hline LC10-11 & $41.1 \pm 2.8$ & \multirow[t]{2}{*}{0.70} & \multirow{2}{*}{$40.3 \pm 2.0$} & \multirow{2}{*}{$41.1 \pm 2.7$} & \multirow{2}{*}{$\begin{array}{l}40.1-36.7 \\
(40.1-38.3)\end{array}$} \\
\hline LC11-3 & $39.9 \pm 1.8$ & & & & \\
\hline \multicolumn{6}{|c|}{ US05 - Sterile } \\
\hline LC11-1 & $42.4 \pm 2.1$ & - & - & - & - \\
\hline \multicolumn{6}{|c|}{ US06 - Châtelperronian } \\
\hline LC10-13 & $38.4 \pm 1.8$ & \multirow[t]{3}{*}{0.024} & \multirow[t]{3}{*}{${ }^{\mathrm{a}} 43.1 \pm 2.2$} & \multirow[t]{3}{*}{-} & \multirow{3}{*}{$\begin{array}{l}46.0-40.6 \\
(42.8-40.6)\end{array}$} \\
\hline LC10-15 & $43.3 \pm 2.3$ & & & & \\
\hline LC11-2 & $43.1 \pm 2.1$ & & & & \\
\hline \multicolumn{6}{|c|}{ US07 - Sterile } \\
\hline LC10-16 & $47.3 \pm 2.3$ & - & - & $42.9 \pm 4.2$ & - \\
\hline \multicolumn{6}{|c|}{ US08 - Mousterian } \\
\hline LC10-17 & $50.7 \pm 2.5$ & 0.41 & $51.3 \pm 3.0$ & & $45.8-38.6$ \\
\hline LC10-18 & $50.9 \pm 2.4$ & & & & $(45.8-42.3)$ \\
\hline LC10-19 & $52.5 \pm 3.6$ & & & $49.2 \pm 3.6$ & \\
\hline
\end{tabular}

${ }^{a}$ The weighted mean OSL age does not include LC10-13.

(Fig. 2C), we collected 9 samples from the upper- and lower-most parts of the archaeological sequence. This is the only part where the Mousterian (US08) and the sterile layer (US07) separating it from the overlying CP (US06) has so far been exposed. So, we collected 3 samples from the Mousterian and one sample from the sterile layer. We also collected one sample from the CP to chronologically tie the $\mathrm{CP}$ found here to the $\mathrm{CP}$ found on the opposite side of the site (Fig. 2A). Higher up the sequence, we collected one sample from the UEA (US02), two samples from the sterile US01 and one sample from a clay layer stratified between US01 and US02, in which some isolated UEA artefacts were found. Good lateral and vertical coverage of the site was obtained with the necessary replicate samples from the same stratigraphic units to allow spatiotemporal connections to be made across the site.

\section{Sample preparation and measurement equipment}

For OSL and MET-pIRIR dating, quartz and K-feldspar grains were chemically extracted using standard procedures from the bulk sediment samples and separated using three different densities $\left(2.70,2.62\right.$ and $\left.2.58 \mathrm{~g} / \mathrm{cm}^{3}\right)$ of sodium polytungstate solution. Grains of $180-212 \mu \mathrm{m}$ in diameter were selected for dating of quartz, and grains $90-125 \mu \mathrm{m}$ in diameter were selected for dating of feldspar. The quartz grains were etched using $40 \% \mathrm{HF}$ acid for 45 min to dissolve any remaining feldspar grains that may be present in the quartz separate and to remove the alpha-irradiated layer around the surface of the grains. The K-feldspar grains were etched using $10 \% \mathrm{HF}$ acid for $40 \mathrm{~min}$ to clean the surface of the grains and to also reduce the alpha-irradiated layer around the grain surface.

The quartz OSL measurements and K-feldspar IRSL measurements were made on two different automated Risø TL-DA-20 luminescence readers equipped with a single grain laser $(532 \mathrm{~nm})$ and IR diodes $(870 \Delta 40 \mathrm{~nm})$ for stimulation of quartz and feldspar, respectively (Bøtter-Jensen et al., 2003). Irradiations were carried out within each luminescence reader using calibrated ${ }^{90} \mathrm{Sr} /{ }^{90} \mathrm{Y}$ beta sources. The ${ }^{90} \mathrm{Sr} /{ }^{90} \mathrm{Y}$ beta sources were calibrated using a range of known gamma-irradiated quartz standards for both multi-grain aliquots and individual grain positions. Spatial variations in beta dose rate for individual grain positions were taken into account, based on measurements made using the same gamma-irradiated quartz standards (e.g., Ballarini et al., 2006). The ultraviolet OSL emissions were detected by an Electron Tubes Ltd 9235QA photomultiplier tube fitted with Hoya U-340 filters. The IRSL signals were detected using the same type of photomultiplier tube with the stimulated luminescence passing through a filter pack containing Schott BG-39 and Corning 7-59 filters, which provides a UV/blue transmission window (320-480 nm). All single grain quartz measurements were made using standard single grain discs (gold-plated aluminium discs drilled with 100 holes that are each $300 \mu \mathrm{m}$ in diameter and $300 \mu \mathrm{m}$ deep) (Bøtter-Jensen et al., 2000). All multi-grain K-feldspar measurements were made using $9.8 \mathrm{~mm}$ diameter stainless steel discs onto which a $5 \mathrm{~mm}$ diameter spot was sprayed in the centre with "Silkospray" silicone oil. A monolayer of several hundred grains was adhered to the surface of each disc to form an aliquot for measurement.

\section{Single grain OSL}

\subsection{Measurement procedures}

All measurements were made using the single aliquot regenerative-dose (SAR) procedure described elsewhere (e.g., Galbraith et al., 1999; Murray and Wintle, 2000; Jacobi et al., 2006). The SAR procedure involves measuring the OSL signals from the natural (burial) dose and from a series of regenerative doses (given in the laboratory by means of the calibrated ${ }^{90} \mathrm{Sr} /{ }^{90} \mathrm{Y}$ beta source), each of which was preheated at $260{ }^{\circ} \mathrm{C}$ for $10 \mathrm{~s}$ prior to optical stimulation by an intense, green $(532 \mathrm{~nm})$ laser beam for $2 \mathrm{~s}$ at $125^{\circ} \mathrm{C}$. A fixed test dose $\left(\sim 11 \mathrm{~Gy}\right.$, preheated at $220^{\circ} \mathrm{C}$ for $\left.5 \mathrm{~s}\right)$ was given after each natural and regenerative dose, and the induced OSL signals were used to correct for any sensitivity changes during the SAR sequence. A duplicate regenerative dose was included in the procedure, to check on the adequacy of this sensitivity correction. As a check on possible contamination of the etched quartz grains by feldspar inclusions, we also applied the OSL IR depletion-ratio test (Duller, 2003) to each grain at the end of the SAR sequence, using an infrared exposure of $40 \mathrm{~s}$ at $50^{\circ} \mathrm{C}$.

The $D_{e}$ values were estimated from the first $0.22 \mathrm{~s}$ of OSL decay, with the mean count recorded over the last $0.3 \mathrm{~s}$ being subtracted as background (Fig. 3 main plot). The dose-response data were fitted using a saturating exponential function, and the sensitivitycorrected natural OSL signal was projected on to the fitted dose-response curve to obtain the $D_{e}$ by interpolation (Fig. 3 inset plot). The uncertainty on this estimate (from photon counting statistics, curve fitting uncertainties, the error associated with the calibration of individual positions, and an allowance of $2 \%$ per OSL measurement for instrument irreproducibility) was determined by Monte Carlo simulation, using the procedures described by Duller (2007). The final age uncertainty includes a further $2 \%$ (added in quadrature) to allow for any bias in the beta source calibration.

Aberrant grains were rejected using the quality-assurance criteria described and tested previously (Jacobs et al., 2008a). 

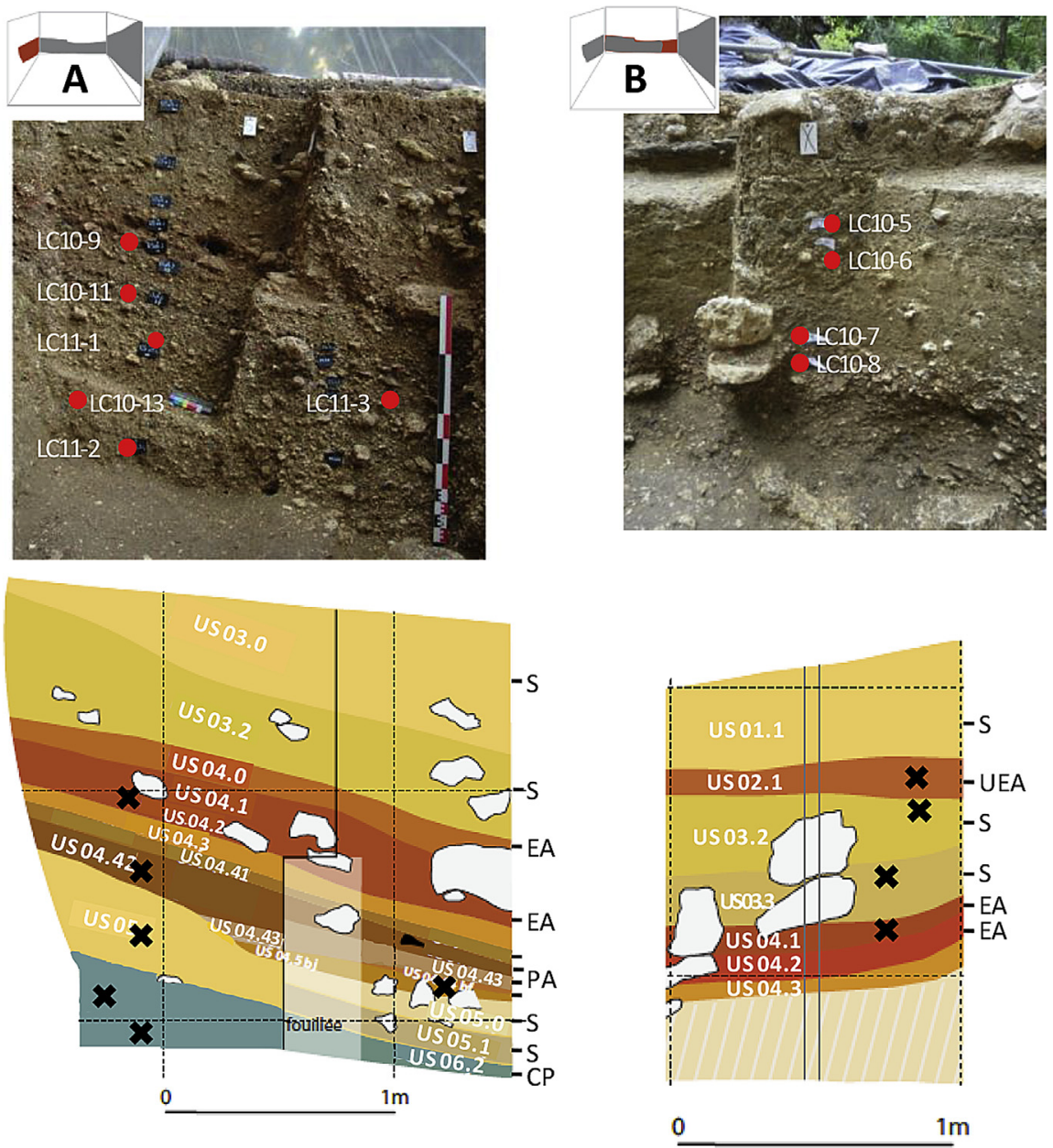
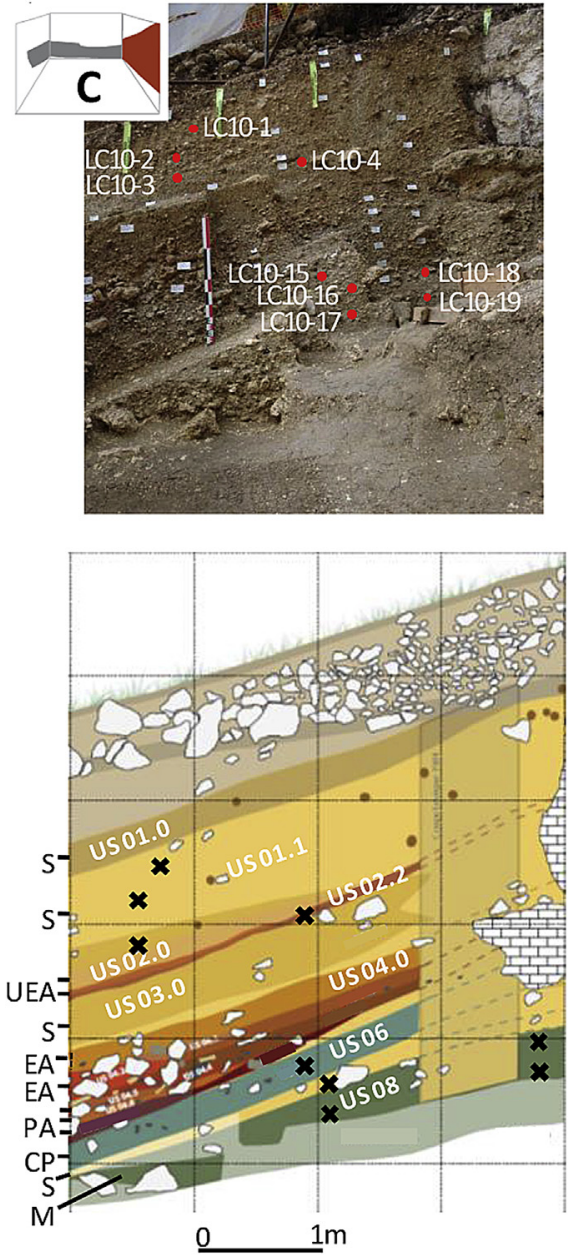

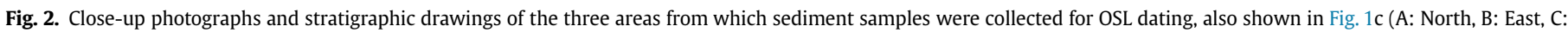

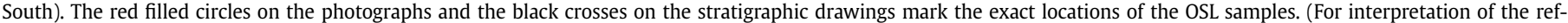
erences to colour in this figure legend, the reader is referred to the web version of this article.)

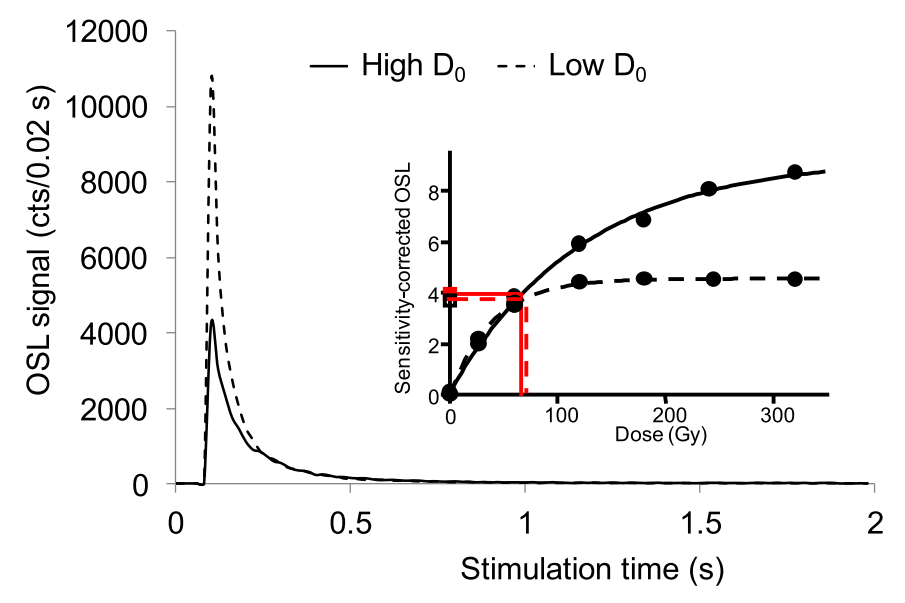

Fig. 3. OSL decay curves for two quartz grains that show similar decay curve characteristics and $D_{e}$ values (shown in red), but different dose response curves (inset plot) and characteristic saturation dose $\left(D_{0}\right)$ values. These two grains represent the two extremes of a wide range of dose response curve shapes and $D_{0}$ values found for grains from Les Cottés. Further details are provided in Supporting Information. (For interpretation of the references to colour in this figure legend, the reader is referred to the web version of this article.)
Table S2 provides the details for all samples and the reasons for rejecting particular single grains. Further details about the characteristics of the rejected grains are provided in Supporting Information.

Under the experimental conditions described above, we recovered correct dose estimates for single grains of quartz from three samples, one each from the top (LC10-4), middle (LC10-11) and bottom (LC10-17) of the sedimentary sequence. Grains of each sample were first bleached with natural sunlight for 3 days, and then given a known dose ( $80 \mathrm{~Gy}$ ) in the laboratory. The weighted mean ratios of measured to given dose obtained for the three samples (LC10-4 - 0.99 $\pm 0.02, n=102$; LC10-11 - $0.99 \pm 0.02$, $n=79$; LC10-17 $-0.97 \pm 0.02, n=57$ ) are statistically consistent with unity, which shows that the chosen SAR procedures can accurately recover a known dose under controlled conditions (Fig. S1). Overdispersion (OD) values of $7.8 \pm 1.6,5.8 \pm 2.5$ and $2.4 \pm 3.6 \%$ were obtained for the three dose recovery data sets, respectively. Overdispersion refers to the relative spread in the dose distribution above and beyond that associated with the measurement uncertainties of individual grains, and was calculated using the Central Age Model (CAM) (Galbraith et al., 1999; Galbraith and Roberts, 2012). If all of the scatter were due to measurement error alone, then the OD value would be zero, but this is commonly not the case for quartz grains even under ideal circumstances (Jacobs 
and Roberts, 2007; Arnold and Roberts, 2009; Galbraith and Roberts, 2012).

Further details about the general characteristics of the OSL signal from individual grains are provided in Supporting Information.

\section{2. $D_{e}$ distributions and interpretation}

The $D_{e}$ values for all accepted grains from all samples are displayed, in stratigraphic order, as radial plots in Fig. S9. An example radial plot of a single grain $D_{e}$ distribution for sample LC10-07 is presented in Fig. 4. A total of 20,800 grains were measured for all 19 samples, but only 3007 grains (14.5\% of the total) passed the rejection criteria (Table S2). The majority of the grains ( $71 \%$ of the total) were rejected because they emitted no measurable luminescence signal in response to a $\sim 11 \mathrm{~Gy}$ beta dose administered in the laboratory (Fig. S2). Table 1 contains information about the number of grains used for $D_{e}$ determination, the $D_{e}$ overdispersion values and the modelled $D_{e}$ estimate used to calculate the age of each sample.

It is apparent from the radial plots (Fig. S9) and overdispersion values (Table 1 ) that, for all samples, the individual $D_{e}$ values are spread more widely than can be accounted for statistically if they were all consistent with a common value. The overdispersion values range between $19 \pm 2$ (LC11-03) and $32 \pm 4 \%$ (LC10-15) (Table 1), and, for each sample, the vast majority of $D_{e}$ values are spread randomly around a central value (Fig. S9). Such samples are typical of those that are known or are thought to have been wellbleached prior to burial and remained undisturbed since burial (Jacobs and Roberts, 2007; Arnold and Roberts, 2009; Galbraith and Roberts, 2012). None of the samples show the presence of more than one discrete dose component, whereas multiple components would be expected of samples composed of grains that have statistically different ages and that were mixed together after deposition. This finding is in accordance with our stratigraphic observations of archaeologically sterile sedimentary layers clearly separated from the major archaeological deposits (Fig. 2). Some of

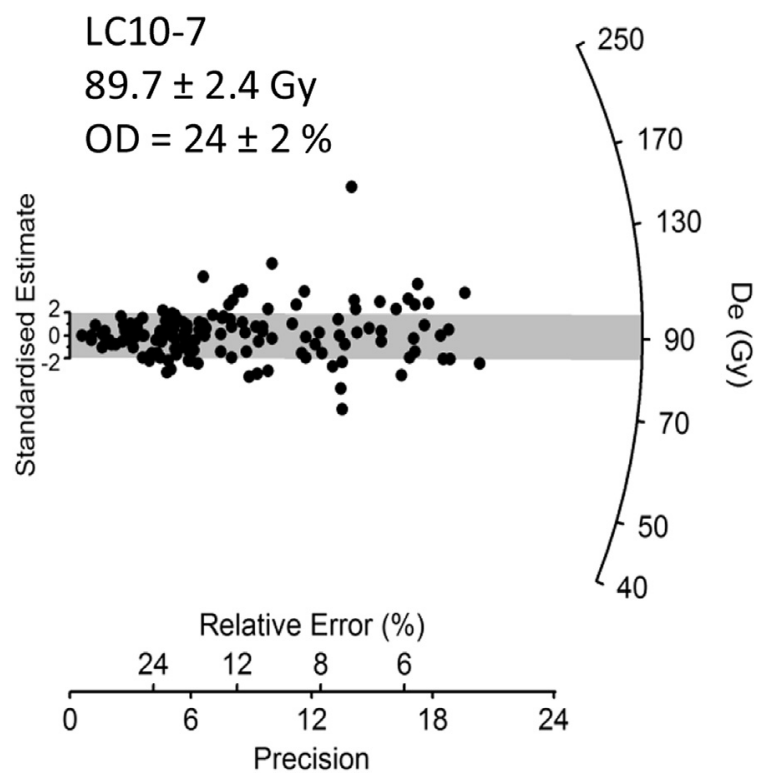

Fig. 4. Radial plot of the $D_{e}$ distribution for the 123 accepted grains for sample LC10-7. The grey band is centred on the weighted mean $D_{e}$ determined using the Central Age Model and used in the final age calculation. Radial plots for all 19 samples are presented in Fig. S9. the samples show the occasional high or low $D_{e}$ outlier (e.g., LC1015, LC10-19 and LC11-02). Because these outliers are so few, they do not skew the central $D_{e}$ value, but the uncertainty on the $D_{e}$ value reflects their presence (i.e., the error on the weighted mean is larger). We attribute these broader-than-expected $D_{e}$ distributions to small-scale differences in the beta dose received by individual grains, and the homogeneous spread on the radial plot is due to the ubiquitous inclusion of limestone clasts into the otherwise sandyclayey sediment matrix.

Because only a single discrete $D_{e}$ component can be detected in each of our samples, we calculated the weighted mean of the single-grain $D_{e}$ values using the CAM to obtain the most accurate estimate of $D_{e}$ for age calculation. The CAM assumes that the $D_{e}$ values for all grains are centred on some average value of $D_{e}$ and has the virtue of taking any overdispersion into account when determining the weighted mean and its standard error.

\section{Multiple-aliquot MET-pIRIR results and interpretation}

In this study, we also applied the MET-pIRIR procedure to obtain $D_{e}$ estimates on the K-feldspar grains. This procedure utilises the IRSL signals measured by progressively increasing the stimulation temperature from 50 to $250^{\circ} \mathrm{C}$ in $50^{\circ} \mathrm{C}$ steps. It has previously been reported that MET-pIRIR signals obtained at elevated temperatures $\left(>200^{\circ} \mathrm{C}\right.$ ) show negligible rates of anomalous fading and, hence, require no fading correction, and that the corresponding MET-pIRIR ages are consistent with independent or quartz OSL ages for various sedimentary samples from China deposited in the last $300 \mathrm{ka}$ ( $\mathrm{Li}$ and Li, 2011, 2012). In an earlier study, however, we reported that the K-feldspars extracted from samples collected from Les Cottés exhibit a large proportion ( $30 \%)$ of non-bleachable or residual signal in their MET-pIRIR signals, even after a prolonged sunlight bleach lasting several days (Li et al., 2013). We also demonstrated that the residual signal is strongly dose dependent, which may lead to large uncertainty in $D_{e}$ estimation (Li et al., 2013). To overcome this problem in this study, we used a multiple-aliquot method to avoid having to make the residual dose correction (Table S3). Several groups of natural aliquots (each comprised of 4-6 aliquots) of each sample were bleached using a solar simulator (Dr. Hönle UVACUBE 400) for $2 \mathrm{~h}$, which has been shown to be sufficient to remove most of the bleachable signal (Li et al., 2013). Each group was then given a different regenerative dose and preheated at $300{ }^{\circ} \mathrm{C}$ for $60 \mathrm{~s}$, followed by successive MET-pIRIR measurements at $50,100,150,200$ and $250{ }^{\circ} \mathrm{C}$ to stimulate regenerative MET-pIRIR signals $\left(L_{x}\right)$. The aliquots were then given a test dose of $44 \mathrm{~Gy}$, followed by the same preheat and series of MET-pIRIR stimulations to measure their respective sensitivities $\left(T_{x}\right)$. The sensitivity-corrected MET-pIRIR signal $\left(L_{x} / T_{x}\right)$ from each group was then plotted against its regenerative dose to construct a dose response curve. A separate group of natural aliquots was measured in the same way to obtain the natural signal $\left(L_{N}\right)$ and its sensitivity $\left(T_{N}\right)$. The full procedure is summarised in Table S3. Because different groups of aliquots were bleached for the same period of time, the residual signals are assumed to be the same, so no residual correction is required. The dose response curve for the MET-pIRIR signal of sample LC10-03, measured at a stimulation temperature of $250{ }^{\circ} \mathrm{C}$, is shown in Fig. 5a.

The advantage of using the MET-pIRIR procedure, compared to the two-step pIRIR procedure, is that multiple ages are obtained for a sample (at different stimulation temperatures). The expectation is that the signal measured at the lowest temperature will yield the youngest apparent age, because this signal is still subjected to complications associated with anomalous fading. As the temperature is increased step-wise, the ages should increase until a plateau is reached, if a stable or non-fading component has been measured 
(Li and Li, 2011, 2012). This can also be illustrated as a $D_{e_{-}}$Temperature $\left(D_{e_{-}} \mathrm{T}\right)$ plot, where the $D_{e}$ values are plotted as a function of their stimulation temperature. The $D_{e_{-}} \mathrm{T}$ plot for sample LC10-11 is shown in Fig. 5b. The most accurate age will be obtained from the $D_{e}$ plateau region, indicated as a stippled line. The corresponding 'age plateau' plot is shown in Fig. 6c. A plateau was reached for all 5 samples measured in this study and the final ages are based on the $D_{e}$ values and uncertainties obtained for the MET-pIRIR signal stimulated at $250{ }^{\circ} \mathrm{C}$.

\section{Environmental dose rate measurements and results}

The total environmental dose rate to etched sand-sized grains of quartz and feldspar consists of contributions from beta, gamma and cosmic radiation external to the grains, plus an internal dose rate due to radioactive inclusions. Both minerals receive a small internal alpha dose from $U$ and Th inclusions, while K-feldspar grains also have a significant internal beta dose rate from the radioactive decay of ${ }^{40} \mathrm{~K}$ and ${ }^{87} \mathrm{Rb}$.

The external beta dose rates for all 19 samples were measured directly using a GM-25-5 low level beta counter (Bøtter-Jensen and Mejdahl, 1988), and allowance was made for the effect of grain size and HF acid etching on beta dose attenuation. For five of the samples, we made two sets of three measurements several weeks apart,
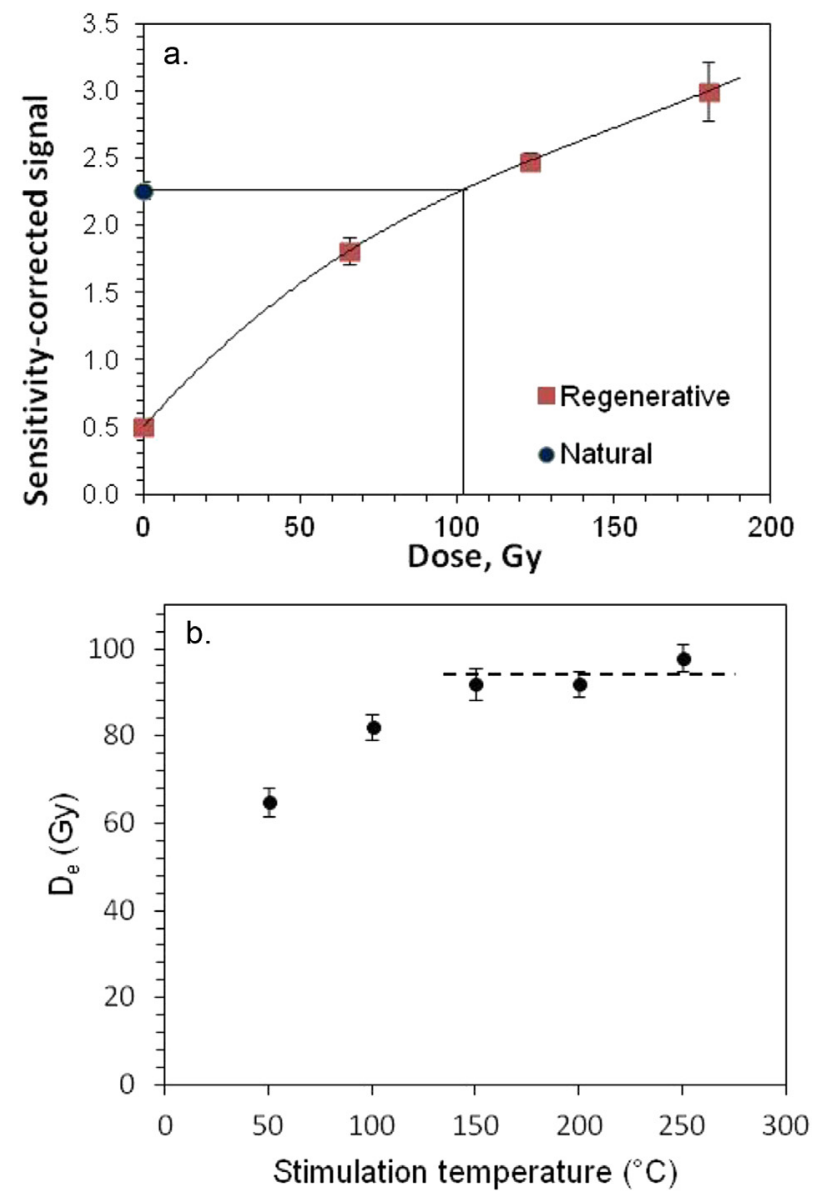

Fig. 5. a. Multiple-aliquot dose response curve for K-feldspar grains from sample LC103 , constructed using the MET-pIRIR signals stimulated at $250{ }^{\circ} \mathrm{C}$. Each data point represents the average of 4-6 aliquots. b. Equivalent dose_Temperature $\left(D_{e_{-}} \mathrm{T}\right)$ plot for sample LC10-11. The stippled line indicates the plateau obtained for $D_{e}$ values at the highest stimulation temperatures. to check the reproducibility of our measurements over time. The average ratio of the first/second set of measurements was $1.007 \pm 0.023$, which is well within the reproducibility error of $3-4 \%$ measured for each of the samples.

The gamma dose rates for all 19 samples were measured directly at the point of sampling with a $\mathrm{NaI}(\mathrm{Tl})$ detector. This approach takes into account the obvious spatial heterogeneity in the gamma radiation field (a radius of $\sim 40 \mathrm{~cm}$ ) around each sample. The dose rates were estimated using the "threshold" technique (Mercier and Falguères, 2007), which gives an estimate of the combined gamma dose rate from $U$ and Th chains and from ${ }^{40} \mathrm{~K}$. The detector was calibrated using the doped concrete blocks at Oxford (Rhodes and Schwenninger, 2007).

By measuring the external dose rates in these ways, we have implicitly assumed that the present state of (dis)equilibrium in the $\mathrm{U}$ and Th decay chains has prevailed throughout the period of sample burial. These dose rates were corrected for the measured (field) water content of each sample. For water content measurement, we collected sediment at the back of each sample hole $\sim 20-30 \mathrm{~cm}$ into the section wall, and away from the dried out excavated faces; we then immediately sealed the bags tightly to prevent drying of the sediments before measurement in the laboratory. We assume that these field values are representative of the average long-term water contents, but note that, for quartz grains, an increase in water content of $1 \%$ will result in a $~ 1 \%$ increase in age. The effect on feldspar grains is less, because the internal dose rate is not affected by water content. We assigned a relative uncertainty of $\pm 25 \%$ (at $1 \sigma$ ) to accommodate any likely variations over the burial period.

A small, internal alpha dose rate of $0.03 \pm 0.01 \mathrm{~Gy} / \mathrm{ka}$ was assumed for the quartz grains. For the K-feldspars, an internal beta dose rate was calculated by assuming internal ${ }^{40} \mathrm{~K}$ and ${ }^{87} \mathrm{Rb}$ concentrations of $13 \pm 1 \%$ and $400 \pm 100 \mu \mathrm{g} / \mathrm{g}$, respectively (Huntley and Baril, 1997; Huntley and Hancock, 2001; Zhao and Li, 2002; Li et al., 2008). These were converted to dose rates using the conversion factors of Guerin et al. (2012), and corrected for the absorbed dose fraction. For K-feldspar grains of 90-125 $\mu \mathrm{m}$ diameter, this yields an effective internal beta dose rate of $0.48 \pm 0.04 \mathrm{~Gy} / \mathrm{ka}$, which is a significant fraction (between 17 and $24 \%$ ) of the total dose rate.

The cosmic-ray dose rates were estimated from the equations provided by Prescott and Hutton (1994), taking into account the burial depth of each sample (averaged over the entire period of burial), the density of sediment overburden $\left(1.8 \mathrm{~g} / \mathrm{cm}^{3}\right)$, and the altitude $(90 \mathrm{~m})$ and geomagnetic latitude $\left(49.3^{\circ}\right)$ of Les Cottés. We also took into consideration the $\cos ^{2} \varphi$-zenith angular distribution of cosmic rays (Smith et al., 1997) to allow for the extent of rock shielding of the deposit by the adjacent limestone cliff into which the cave extends. We assigned a relative uncertainty of $\pm 15 \%$ to these dose rates to account for the systematic uncertainty in the primary cosmic-ray intensity (Prescott and Hutton, 1994).

For the quartz samples, the total dose rates range between $1.59 \pm 0.06$ and $2.45 \pm 0.08 \mathrm{~Gy} / \mathrm{ka}$. The feldspar samples have the same relative range, but are consistently $\sim 0.5 \mathrm{~Gy} / \mathrm{ka}$ higher due to the internal beta dose rate. The majority of the quartz samples fall within a much narrower range of dose rates $(1.59 \pm 0.06$ to $1.96 \pm 0.09 \mathrm{~Gy} / \mathrm{ka}$ ), and only the few samples collected from US03 and US02 have slightly higher total dose rates $(2.23 \pm 0.08$ to $2.45 \pm 0.08 \mathrm{~Gy} / \mathrm{ka}$ ). The latter is directly related to the much higher clay content, and much lower limestone rubble content, compared to the over- and under-lying units. For all samples, the uncertainty associated with the total dose rate represents the quadratic sum of all known and estimated sources of random and systematic error. 

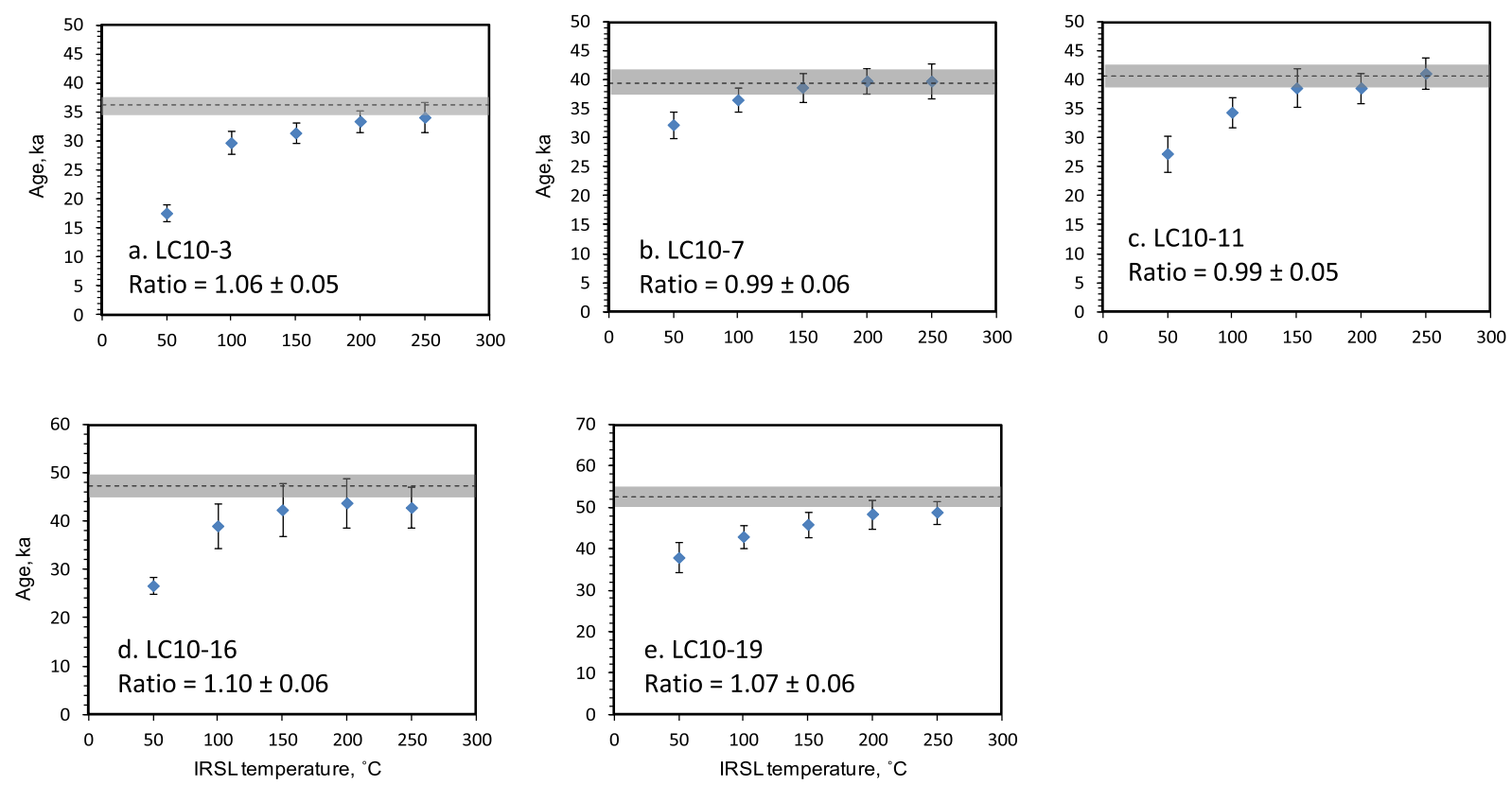

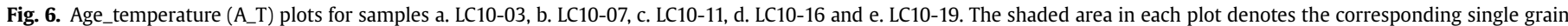

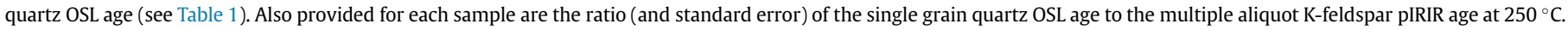

\section{Age estimates and comparisons}

\subsection{Single grain OSL chronology}

The $D_{e}$ and dose rate information is presented in Table 1 , together with the final ages for all samples derived from single grains of quartz. Uncertainties on the ages are given as $1 \sigma$.

For each of the archaeological units, we have calculated ages for at least two and, in some cases, three samples to allow us to check the reproducibility of our ages within any unit and across excavation space. We used the statistical (homogeneity) test of Galbraith (2003) to determine whether the ages from each unit are selfconsistent (i.e., the spread in ages for each layer is statistically compatible with the size of the age uncertainties). The calculated $P$ values are provided in Table 2, alongside the individual ages for each archaeological unit. The calculated $P$-values are all $>0.05$ (except for unit US06), which, by convention, suggests that the OSL ages are self-consistent within each unit (US). We accordingly calculated a weighted mean age for each unit, assuming that the individual ages represent a series of events spread over a time interval that is short compared to the size of the uncertainties associated with each individual age in that unit.

The weighted mean OSL ages presented in Table 2 were then used to construct a chronological framework for sediment deposition at Les Cottés. Using this chronology, ages have been inferred for each of the associated archaeological industries. A noteworthy feature is that the weighted mean ages are all in the correct stratigraphic order. An age of $51 \pm 3 \mathrm{ka}$ is obtained for the uppermost and exposed levels of the Mousterian (US08). The overlying sterile unit (US07) is dated by a single OSL age to $47 \pm 2 \mathrm{ka}$, which, in turn, is overlain by sediments containing the Châtelperronian (CP) industry in US06. One of the US06 ages (LC10-13) is younger and statistically inconsistent with the other two ages (see $P$-value in Table 2), and the age for the overlying sterile unit. This age is, thus an outlier, and we have excluded LC10-13 from the weighted mean age of $43.1 \pm 2.2 \mathrm{ka}$ obtained for the $\mathrm{CP}$. This age is very similar to the range of ${ }^{14} \mathrm{C}$ ages presented for the $\mathrm{CP}$ at Grotte du Renne (39.5-45.0 ka cal BP; Higham et al., 2010; Hublin et al., 2012). The
$\mathrm{CP}$ is separated from the Proto-Aurignacian (PA) by US05, dated to $42 \pm 2 \mathrm{ka}$, which is only slightly older than the three, statistically consistent, weighted mean ages of $40 \pm 2,41 \pm 2$ and $41 \pm 2 \mathrm{ka}$ obtained for the PA (US04 lower), Early Aurignacian (EA) (US04 upper) and the sterile layer capping these two industries (US03), respectively. We are unable to statistically separate the PA from the EA using single grain OSL dating, but note that the ${ }^{14} \mathrm{C}$ chronology for Les Cottés by Talamo et al. (2012) could also not resolve these age and that our ages of $41 \pm 2 \mathrm{ka}$ for the PA and EA are also consistent with a range of ${ }^{14} \mathrm{C}$ ages from sites throughout Europe summarised in Higham et al. (2012) and Banks et al. (2013). The Upper Early Aurignacian (UEA) in Unit US02 is dated to $37.2 \pm 1.5 \mathrm{ka}$, which is overlain by a thick sterile unit (US01) dated to $35.5 \pm 1.5 \mathrm{ka}$. The entire sedimentary sequence so far exposed at Les Cottés thus spans a relatively brief time interval of seventeen millennia, from $\sim 52$ to $\sim 35 \mathrm{ka}$.

\subsection{Single grain OSL and multiple aliquot pIRIR comparisons}

The $D_{e}$ and dose rate information for the five samples for which we measured the MET-pIRIR signals from K-feldspar grains are also presented in Table 1 . In contrast to the single grain OSL measurements on quartz, these $D_{e}$ values resulted from measurements of thousands of K-feldspar grains for which an 'average' result was then obtained and subsequently used to calculate the final $D_{e}$ value and age. Age_Temperature (A_T) plots for all five samples are presented in Fig. 6a-e, and show the ages calculated for the MET-pIRIR signal at each stimulation temperature. Also shown in Fig. 6, as a grey band, is the corresponding single grain OSL age for each sample and its $1 \sigma$ error. The MET-pIRIR ages and their uncertainties are also provided in Table S4. As expected, the low temperature MET-pIRIR signals (50 and $100{ }^{\circ} \mathrm{C}$ ) significantly underestimate the quartz age, whereas the ages obtained from the plateau region are consistent with the quartz OSL age (i.e., within $1 \sigma$ ). This consistency is also evident from the ratio of the single grain quartz OSL age over the $250{ }^{\circ} \mathrm{C}$ pIRIR feldspar age (Fig. 6a-e). This agreement between the single grain quartz OSL and multiple-aliquot MET-pIRIR feldspar ages has two important implications: 1) incomplete bleaching 
of the OSL and pIRIR signals is not a problem. The pIRIR $250{ }^{\circ} \mathrm{C}$ signal requires a longer sunlight exposure time than the OSL signal to empty the relevant traps and reset the 'clock', so the consistency in their ages suggests that both signals were completely reset at the time of deposition. 2) The effect of small-scale differences in the beta dose delivered to individual quartz grains, and the rejection of single grains on the basis of their malign OSL behaviours, has not biased the OSL ages.

We, thus, feel confident that our single grain OSL 'clock' is performing accurately and that the single grain OSL chronology is reliable.

\subsection{OSL and ${ }^{14} \mathrm{C}$ comparisons}

Talamo et al. (2012) reported ${ }^{14} \mathrm{C}$ ages for 27 bone samples, of which 16 samples displayed clear evidence of human activity (i.e., cut marks or retouch). All samples were pretreated using the latest molecular ultrafiltration method and they conducted an interlaboratory measurement procedure where samples with enough collagen were split in three, and measured on two different accelerator mass spectrometry (AMS) instruments. Each of the three sample splits were graphitised in the different laboratories, but the graphitised sample from Max Planck was measured on the same
AMS as the samples graphitised in Oxford. Excellent measurement reproducibility was obtained and a weighted mean of the different measurements made on the split samples were used to calculate the final ages. It is important to note that the latter reproducibility check is not a test of sample purity, since all sample splits were pretreated simultaneously in one laboratory (EVA-MPI). All but two of the samples contained the required $>1 \%$ collagen and had $\mathrm{C}: \mathrm{N}$ ratios that fell well within the accepted range (2.9-3.6) for modern humans and other animals. Also, the majority of samples had \% $N$ values for collagen that indicate good protein quality. In modern samples, this is typically $\sim 16 \%$ and anything less than $\sim 11 \%$ is thought to be problematic. Only two samples from the Mousterian had $\% N$ values less than 11\% (see Table 3 in Talamo et al., 2012). All $27{ }^{14} \mathrm{C}$ ages are summarised in Table S5, together with their 68.2 $(1 \sigma)$ and $95.4 \%(2 \sigma)$ probability calibrated age ranges determined using IntCal13 (Reimer et al., 2013).

In general, the ${ }^{14} \mathrm{C}$ ages of each stratigraphic unit agree with their stratigraphic position, with the exception of 8 outliers identified by Talamo et al. (2012) (highlighted in grey in Table S5). These outliers follow no systematic trend: in the EA and CP, the 'outlier' ages are older, whereas in the PA and $\mathrm{M}$ they are younger. Talamo et al. (2012) were not able to determine the reason for these aberrant ages, but they dismissed mixing on the basis of

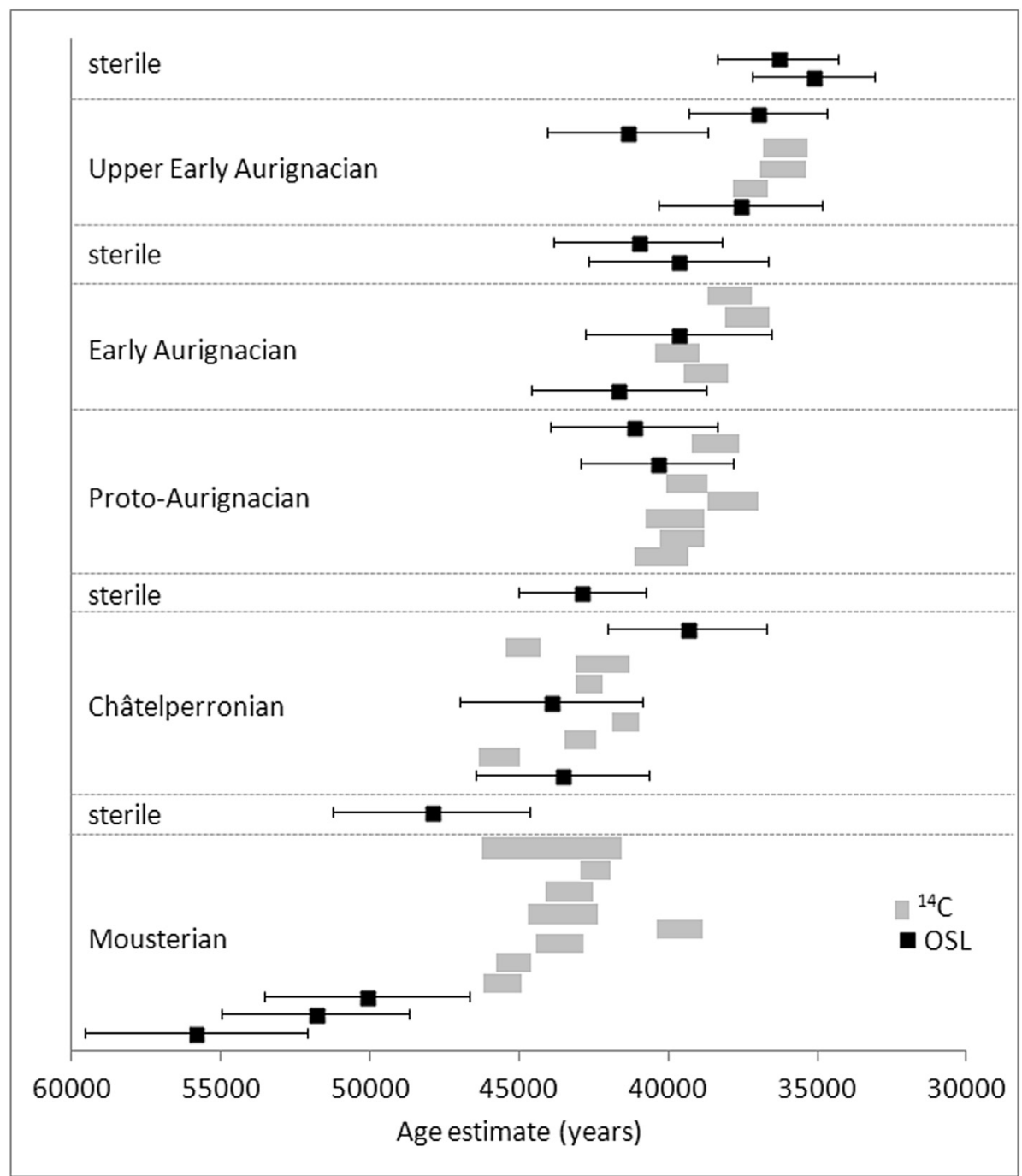

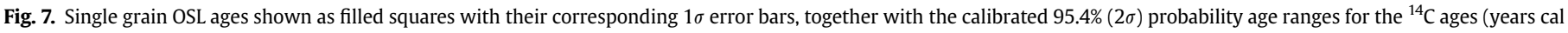
$\mathrm{BP})$ reported by Talamo et al. (2012) and provided in Table S5 in supplementary information. The data are plotted in stratigraphic order. 
stratigraphy. So, in their construction of the final ${ }^{14} \mathrm{C}$ chronology, these outliers were omitted and they obtained start and end dates for each of the cultural industries using a Bayesian model built in OxCal. The exact modelled start and end dates are not provided in Talamo et al. (2012), but it can be read from their Fig. 4. From this, it is evident that the entire excavated archaeological sequence represents only $\sim 10 \mathrm{ka}$ of deposition and occupation, ranging from $\sim 46 \mathrm{ka}$ at the start of the so-far exposed Mousterian levels to $\sim 36 \mathrm{ka}$ at the end of the upper EA; this is $\sim 7$ ka shorter than the single grain OSL chronology.

We have summarised in Table 2 all the OSL and ${ }^{14} \mathrm{C}$ age ranges. The ${ }^{14} \mathrm{C}$ age ranges are based on the oldest and youngest calibrated ages at $68.2 \%$ probability $(1 \sigma)$ and include all ${ }^{14} \mathrm{C}$ age estimates from any given unit, including those identified by Talamo et al. (2012) as 'outliers'. We have also provided, in brackets and italicised, the age ranges, excluding those ages identified as 'outliers'. The OSL ages for all samples from all units and the individual calibrated ${ }^{14} \mathrm{C}$ ages at $95.4 \%$ probability are also graphically displayed in Fig. 7. From this figure, it can be seen that ages from both methods are in excellent agreement for all units where comparisons exist, including ages for the CP, PA, EA and UEA. This further confirms the accuracy of our single grain OSL 'clock'.

The only discrepancy between the two sets of ages is for US08, the Mousterian. The OSL ages for this unit, and the age for the overlying sterile unit (US07), are systematically older than the ${ }^{14} \mathrm{C}$ ages. Since we have treated the Mousterian OSL samples in an identical way to those collected from the rest of the sequence, and the sedimentary context are similar to the upper levels, we do not believe that the problem resides in the OSL dating. We have also tested the sensitivity of our ages to changes in, for example, moisture content. To obtain OSL ages consistent with the ${ }^{14} \mathrm{C}$ ages of US08, we would need to assume that the sediments had been completely dry ( $0 \%$ water content) for the entire period of burial; even then, the OSL ages would only be consistent with the upper end of the ${ }^{14} \mathrm{C}$ age range. We, therefore, do not believe water content to be the problem. Partial bleaching can also be discounted because of the consistency between the quartz and feldspar ages (see Fig. 6); the MET-pIRIR ages are derived from stimulation of harder-to-bleach traps, so should partial bleaching be a problem then one would expect the ages for the K-feldspars to be overestimated relative to the single grain quartz OSL ages. This is not the case. As a result, we believe that the ${ }^{14} \mathrm{C}$ ages for the Mousterian are likely to be underestimates of the true age of the Mousterian at Les Cottés. This may be due to very small-scale contamination of the bone samples that has not been removed by the ultrafiltration pretreatment procedure and that was not detected by any of the internal tests to validate sample purity. The same issue of age underestimation may also afflict other bone samples that lie at the upper limit of ${ }^{14} \mathrm{C}$ dating, where even the smallest amount of remnant contamination by modern carbon is sufficient to make the measured ages appear too young. For such samples, we recommend routinely checking ${ }^{14} \mathrm{C}$ age determination against an independent chronometer, such as single grain OSL dating or, where the sediments are not mixed after deposition, by single aliquot OSL and MET-pIRIR.

\section{Concluding remarks}

A common need in archaeology is for events to be arranged in the correct sequence on a standardised timescale. Many techniques are now part of the dating arsenal available to the archaeologist to determine the age of the events of interest. Each method has its own advantages and disadvantages and checking the reliability of results obtained against independently obtained ages is both desirable and a necessity. In this study, we deliberately targeted the site of Les Cottés for single grain OSL dating because: 1) it is one of the rare sites where each of the industries that make up the important Middle to Upper Palaeolithic transition in France is present so that the dating application is addressing an important archaeological question. 2) A recent detailed ${ }^{14} \mathrm{C}$ dating study was undertaken, using the latest state-of-the-art preparation and measurement techniques, namely molecular ultrafiltration of bone that are now commonly applied to similar deposits throughout Europe. 3) Modern excavation and recording techniques are used to demonstrate and assure the stratigraphic integrity of the site (i.e., no significant post-deposition mixing). 4) The site represents a complex depositional and dose rate environment that poses a challenge for single grain OSL dating, so that the study represents a true test of the capabilities of the technique. 5) Potassium-rich (K) feldspar grains are also present to provide the opportunity to measure the luminescence signal from a different mineral with different physical properties to independently test assumptions about pre-depositional resetting of the signal and the effect of small-scale differences in the dose received by individual grains of quartz.

The stratigraphic, within- and between-method consistency of the results suggest that all three dating techniques provide reliable ages using the measurement and analytical approaches described and discussed in this study. Importantly, the results demonstrate that the single grain OSL 'clock' works well and that the rejection of grains with aberrant behaviours does not bias the results and neither does the use of the central age model to combine the individual $D_{e}$ values. It also shows that the direct measurement of the gamma and beta dose rates using our standard laboratory approaches give reliable estimates. Furthermore, if the dating strategy is designed well, good resolution in space and time can be obtained that are not that dissimilar from the distribution of ${ }^{14} \mathrm{C}$ ages from the same unit. Single grain OSL dating can, therefore, be used in sites where ${ }^{14} \mathrm{C}$ is not a possibility or where it is problematic and can play an important role in the debate about the transition from the MP to the UP and in the replacement vs acculturation debate of Neanderthals by Homo sapiens.

\section{Acknowledgements}

This research was funded by the Australian Research Council through Discovery Project grant DP1092843 to Jacobs and a University of Wollongong Vice Chancellor's Post-doctoral Fellowship to Li Bo. We would like to specially thank the owner of the site, the Service Régional de l'Archéologie and the Commission interrégionale de l'Archéologie for permits and permission to Soressi to conduct research at Les Cottés. The Institut national de recherches archéologiques préventives (INRAP) as well as Jean-Jacques Hublin leader of the department of Human Evolution from the Max Planck Institute for evolutionary anthropology in Leipzig, Germany, contributed to fund the excavation. We also thank all members of the excavation and research team for valuable information that has helped us to understand and interpret the OSL data. We acknowledge the useful comments made by two anonymous referees that helped to improve the manuscript.

\section{Appendix A. Supplementary data}

Supplementary data related to this article can be found at http:// dx.doi.org/10.1016/j.jas.2014.11.020.

\section{References}

Aitken, M.J., 1998. An Introduction to Optical Dating. Oxford University Press, Oxford. 
Arnold, L.J., Roberts, R.G., 2009. Stochastic modelling of multi-grain equivalent dose $\left(D_{e}\right)$ distributions: implications for OSL dating of sediment mixtures. Quat. Geochronol. 4, 204-230.

Ballarini, M., Wintle, A.G., Wallinga, J., 2006. Spatial variation of dose rates from beta sources as measured using single grains. Anc. TL 24, 1-8.

Banks, W.E., d'Errico, F., Zilhão, J., 2013. Human-climate interaction during the Early Upper Paleolithic: testing the hypothesis of an adaptive shift between the Proto-Aurignacian and the Early Aurignacian. J. Hum. Evol. 64, 39-55.

Benazzi, S., Douka, K., Fornai, C., Bauer, C.C., Kullmer, O., Svoboda, J., Pap, I., Mallegni, F., Bayle, P., Coquerelle, Condemi, S., Ronchitelli, A., Harvati, K. Weber, G.W., 2007. Early dispersal of modern humans in Europe and implications for Neanderthal behaviour. Nature 479, 525-529.

Bird, M.I., Ayliffe, L.K., Fifield, L.K., Turney, C.S.M., Cresswell, R.G., Barrows, T.T., David, B., 1999. Radiocarbon dating of 'old' charcoal using a wet oxidationstepped combustion procedure. Radiocarbon 41, 127-140.

Bøtter-Jensen, L., Mejdahl, V., 1988. Assessment of beta dose-rate using a GM multicounter system. Nucl. Tracks Radiat. Meas. 14, 187-191.

Bøtter-Jensen, L., Bulur, E., Duller, G.A.T., Murray, A.S., 2000. Advances in luminescence instrument systems. Radiat. Meas. 32, 523-528.

Bøtter-Jensen, L., Andersen, C.E., Duller, G.A.T., Murray, A.S., 2003. Developments in radiation, stimulation and observation facilities in luminescence measurements. Radiat. Meas. 37, 535-541.

Buylaert, J.P., Murray, A.S., Thomsen, K.J., Jain, M., 2009. Testing the potential of an elevated temperature IRSL signal from K-feldspar. Radiat. Meas. 44, 560-565.

Buylaert, J.P., Jain, M., Murray, A.S., Thomsen, K.J., Thiel, C., Sohbati, R., 2012 A robust feldspar luminescence dating method for Middle and Late Pleistocene sediments. Boreas 41, 435-451.

David, B., Roberts, R.G., Magee, J., Mialanes, J., Turney, C., Bird, M., White, C., Fifield, L.K. Tibby, J., 2007. Sediment mixing at Nonda Rock: investigations of stratigraphic integrity at an early archaeological site in northern Australia and implications for the human colonisation of the continent. J. Quat. Sci. 22, 449-479.

De Torres, T., Ortiz, J.E., Grün, R., Eggins, S., Valladas, H., Mercier, N., TisneratLaborde, N., Julia, R., Soler, V., Martinez, A., Sanchez-Moral, S., Canaveras, J.C., Lario, J. Badal, E., Lalueza-Fox, C., Rosas, A., Santamaria, D., De la Rasilla, M. Fortea, J., 2010. Dating of the hominid (Homo neanderthalensis) remains accumulation from El Sidron Cave (Pilona, Asturias, north Spain): an example of a multi-methodological approach to the dating of Upper Pleistocene sites. Archaeometry 52, 680-705.

Douka, K., Hedges, R.E.M., Higham, T.F.G., 2010. Improved AMS ${ }^{14} \mathrm{C}$ Dating of shell carbonatesusing high-precision X-ray diffraction and a novel density separation protocol (CarDS). Radiocarbon 52, 735-752.

Douka, K., Higham, T.F.G., Wood, R., Boscato, P., Gambassinic, P., Karkanas, P., Peresanie, M., Ronchitelli, A.M., 2014. On the chronology of the Uluzzian. J. Hum. Evol. 68, 1-13.

Duller, G.A.T., 2003. Distinguishing quartz and feldspar in single grain luminescence measurements. Radiat. Meas. 37, 161-165.

Duller, G.A.T., 2007. Assessing the error on equivalent dose estimates derived from single aliquot regenerative dose measurements. Anc. TL 25, 15-24.

Feathers, J.K., Holliday, V.T., Meltzer, D.J., 2006. Optically stimulated luminescence dating of Southern High Plains archaeological sites. J. Archaeol. Sci. 33, 1651-1665.

Feathers, J., Kipnis, R., Pilo, L., Arroyo-Kalin, M., Coblentz, D., 2010. How old is Luzia? luminescence dating and stratigraphic integrity at Lapa Vermelha, Lagoa Santa, Brazil. Geoarchaeology 25, 395-436.

Galbraith, R.F., 2003. A simple homogeneity test for estimates of dose obtained using OSL. Anc. TL 21, 75-77.

Galbraith, R.F., Roberts, R.G., 2012. Statistical aspects of equivalent dose and error calculation and display in OSL dating: an overview and some recommendations. Quat. Geochronol. 11, 1-27.

Galbraith, R.F., Roberts, R.G., Laslett, G.M., Yoshida, H., Olley, J.M., 1999. Optical dating of single and multiple grains of quartz from Jinmium rock shelter northern Australia, part 1, experimental design and statistical models. Archaeometry 41, 339-364.

Guerin, G., Mercier, N., Nathan, R., Adamiec, G., Lafrais, Y., 2012. On the use of the infinite matrix assumption and associated concepts: a critical review. Radiat. Meas, 47, 778-785.

Higham, T.F.G., Jacobi, R.M., Ramsey, C.B., 2006. AMS radiocarbon dating of ancient bone using ultrafiltration. Radiocarbon 48, 179-195.

Higham, T.F.G., Jacobi, R.M., Julien, M., David, F., Basell, L., Wood, R., Davies, S.W.G., Bronk Ramsey, C., 2010. The chronology of the Grotte du Renne (France) and implications for the association of ornaments and human remains within the Châtelperronian. Proc. Natl. Acad. Sci. U. S. A. 107, 20234-20239.

Higham, T., 2011. European Middle and Upper Palaeolithic radiocarbon dates are often older than they look: problems with previous dates and some remedies. Antiquity 85, 235-249.

Higham, T., Basell, L., Jacobi, R., Wood, R., Bronk Ramsey, C., Conard, N.J., 2012 Testing models for the beginnings of the Aurignacian and the advent of figurative art and music: the radiocarbon chronology of Geißenklösterle. J. Hum. Evol. 62, 664-676.

Hublin, J.-J., Talamo, S., Julien, M., David, F., Connet, N., Bodub, P., Vandermeersch, B., Richards, M.P., 2012. Radiocarbon dates from the Grotte du Renne and SaintCésaire support a Neandertal origin for the Châtelperronian. Proc. Natl. Acad. Sci. U. S. A. 46, 18743-18748.

Higham, T., Douka, K., Wood, R., Bronk Ramsey, C., Brock, F., Basell, L., Camps, M., Arrizabalaga, A., Baena, J., Barroso-Ruı,, C., Bergman, C., Boitard, C., Boscato, P.
Caparros, M., Conard, N.J., Draily, C., Froment, A., Galvan, B., Gambassini, P., Garcia-Moreno, A., Grimaldi, S., Haesaerts, P., Holt, B., Iriarte-Chiapusso, M.-J., Jelinek, J., Jorda Pardo, J.F., Maıllo-Fernandez, J.M., Marom, J., Maroto, J., Menendez, M., Metz, L., Morin, E., Moroni, A., Negrino, F., Panagopoulou, E., Peresani, M., Pirson, S., de la Rasilla, M., Riel-Salvatore, J., Ronchitelli, A., Santamaria, D., Semal, P., Slimak, L., Soler, J., Soler, N., Villaluenga, A., Pinhasi, R., Jacobi, R., 2014. The timing and spatiotemporal patterning of Neanderthal disappearance. Nature 512, 306-309.

Huntley, D.J., Godfrey-Smith, D.I., Thewalt, M.L.W., 1985. Optical dating of sediments. Nature 313, 105-107.

Huntley, D.J., Baril, M.R., 1997. The K content of the K-feldspars being measured in optical dating or in thermoluminescence dating. Anc. TL 15, 11-13.

Huntley, D.J., Hancock, R.G.V., 2001. The Rb contents of the K-feldspars being measured in optical dating. Anc. TL 19, 43-46.

Jacobi, R.M., Higham, T.F.G., Bronk Ramsey, C., 2006. AMS radiocarbon dating of Middle and Upper Palaeolithic bone in the British Isles: improved reliability using ultrafiltration. J. Quat. Sci. 21, 557-573.

Jacobs, Z., Roberts, R.G., 2007. Advances in optically stimulated luminescence dating of individual grains of quartz from archeological deposits. Evol. Anthropol. 16, $210-223$.

Jacobs, Z., Duller, G.A.T., Wintle, A.G., 2006. Interpretation of single grain $D_{\mathrm{e}}$ dis-

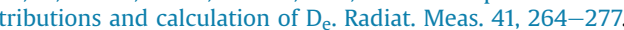

Jacobs, Z., Roberts, R.G., Galbraith, R.F., Deacon, H.J., Grün, R., Mackay, A., Mitchell, P., Vogelsang, R., Wadley, L., 2008a. Ages for the Middle Stone Age of southern Africa: implications for human behavior and dispersal. Science 322, 733-735.

Jacobs, Z., Wintle, A.G., Duller, G.A.T., Roberts, R.G., Wadley, L., 2008b. New ages for the post-Howiesons Poort, late and final Middle Stone Age at Sibudu, South Africa. J. Archaeol. Sci. 35, 1790-1807.

Jacobs, Z., Meyer, M.C., Roberts, R.G., Aldeais, V., Dibble, H., El Hajraoui, M.A., 2011 Single-grain OSL dating at La Grotte des Contrebandiers ('Smugglers' Cave') Morocco: improved age constraints for the Middle Paleolithic levels. J. Archaeol. Sci. 38, 3631-3643.

Li, B., Li, S.H., 2011. Luminescence dating of K-feldspar from sediments: a protocol without anomalous fading correction. Quat. Geochronol. 6, 468-479.

Li, B., Li, S.H., 2012. A reply to the comments by Thomsen et al. on "Luminescence dating of K-feldspar from sediments: a protocol without anomalous fading correction". Quat. Geochronol. 8, 49-51.

Li, B., Jacobs, Z., Roberts, R.G., Li, S.H., 2014. Review and assessment of the potential of post-IR IRSL dating methods to circumvent the problem of anomalous fading in feldspar luminescence. Geochronometria 41, 178-201.

Li, B., Li, S.H., Wintle, A.G., Zhao, H., 2008. Isochron dating of sediments using luminescence of K-feldspar grains. J. Geophys. Res. Earth Surf. 113, F02026.

Li, B., Roberts, R.G., Jacobs, Z., 2013. On the dose dependency of the bleachable and non-bleachable components of IRSL from K-feldspar: improved procedures for the dating of Quaternary sediments. Quat. Geochronol. 17, 1-13.

Mellars, P., 2006. A new radiocarbon revolution and the dispersal of modern humans in Eurasia. Nature 439, 931-935.

Mercier, N., Falguères, C., 2007. Field gamma dose-rate measurements with a $\mathrm{NaI}(\mathrm{Tl})$ detector: re-evaluation of the 'threshold' technique. Anc. TL 25, 1-4.

Murray, A.S., Roberts, R.G., 1997. Determining the burial time of single grains of quartz using optically stimulated luminescence. Earth Planet. Sci. Lett. 152, $163-180$.

Murray, A.S., Wintle, A.G., 2000. Luminescence dating of quartz using an improved single-aliquot regenerative-dose protocol. Radiat. Meas. 32, 57-73.

Pinhasi, R., Higham, T.F.G., Golovanova, L.V., Doronichev, V.B., 2011. Revised age of late Neanderthal occupation and the end of the Middle Paleolithic in the northern Caucasus. Proc. Natl. Acad. Sci. U. S. A. 108, 8611-8616.

Pradel, L., 1961. La grotte des Cottés. L'Anthropologie 65, 229-258.

Pradel, L., 1963. La pointe des Cottés. Bull. Soc. Préhist. Fr. 60, 582-590.

Prescott, J.R., Hutton, J.T., 1994. Cosmic ray contributions to dose rates for luminescence and ESR dating: large depths and long-term time variations. Radiat. Meas. 23, 497-500.

Reimer, P.J., Bard, E., Bayliss, A., Beck, J.W., Blackwell, P.G., Bronk Ramsey, C., Buck, C.E., Cheng, H., Edwards, R.L., Friedrich, M., Grootes, P.M., Guilderson, T.P., Haflidason, H., Hajdas, I., Hatté, C., Heaton, T.J., Hoffmann, D.L., Hogg, A.G., Hughen, K.A., Kaiser, K.F., Kromer, B., Manning, S.W., Niu, M., Reimer, R.W., Richards, D.A., Scott, E.M., Southon, J.R., Staff, R.A., Turney, C.S.M., Van der Plicht, J. 2013. IntCal13 and Marine13 radiocarbon age calibration curves 050,000 years cal BP. Radiocarbon 55, 1869-1887.

Rhodes, E.J., Schwenninger, J.-L., 2007. Dose rates and radioisotopes in the concrete calibration blocks at Oxford. Anc. TL 25, 5-8.

Richter, D., Tostevin, G., Škrdla, P., Davies, W., 2009. New radiometric ages for the Early Upper Palaeolithic type locality of Brno-Bohunice (Czech Republic): comparison of OSL, IRSL, TL and ${ }^{14} \mathrm{C}$ dating results. J. Archaeol. Sci. 36, $708-720$.

Roberts, R., Bird, M., Olley, J., Galbraith, R., Lawson, E., Laslett, G., Yoshida, H., Jones, R., Fullagar, R., Jacobsen, G., Hua, Q., 1998. Optical and radiocarbon dating at Jinmium rock shelter in northern Australia. Nature 393, 358-362.

Roberts, R.G., Galbraith, R.F., Olley, J.M., Yoshida, H., Laslett, G.M., 1999. Optical dating of single and multiple grains of quartz from jinmium rock shelter, northern Australia, part 2, results and implications. Archaeometry 41, 365-395.

Roussel, M. Soressi, M., 2013. Une nouvelle séquence du Paléolithique supérieur ancien aux marges sud-ouest du Bassin parisien : Les Cottés dans la Vienne. In: Bodu, P., et al. (Eds.), Le Paléolithique supérieur ancien de l'Europe du Nord- 
ouest. Réflexions et synthèses à partir d'un projet collectif de recherche sur le centre et le sud du Bassin parisien, actes du colloque de Sens, 15-18 avril 2009. Société Préhistorique Française, Mémoire 56, pp. 283-298.

Smith, M.A., Prescott, J.R., Head, M.J., 1997. Comparison of ${ }^{14} \mathrm{C}$ and luminescence chronologies at Puritjarra rock shelter, central Australia. Quat. Sci. Rev. 16, 299-320.

Soressi, M., Roussel, M., Rendu, W., Primault, J., Rigaud, S., Texier, J.P., Richter, D., Talamo, S., Ploquin, F., Larmignat, B., Tavormina, C., Hublin, J.J., 2010. Les Cottés (Vienne). Nouveaux travaux sur l'un des gisements de référence pour la transition Paléolithique moyen/supérieur. In: Buisson-Catil, J., Primault, J. (Eds.), Mémoire No 384. Association des Publications Chauvinoises, Villefranche-deRouergue, pp. 221-234.

Talamo, S., Soressi, M., Roussel, M., Richards, M., Hublin, J.-J., 2012. A radiocarbon chronology for the complete Middle to Upper Palaeolithic transitional sequence of Les Cottés (France). J. Archaeol. Sci. 39, 175-183.

Thiel, C., Buylaert, J.P., Murray, A., Terhorst, B., Hofer, I., Tsukamoto, S., Frechen, M., 2011. Luminescence dating of the Stratzing loess profile (Austria) - testing the potential of an elevated temperature post-IR IRSL protocol. Quat. Int. 234, $23-31$.
Thomsen, K.J., Murray, A.S., Jain, M., Bøtter-Jensen, L., 2008. Laboratory fading rates of various luminescence signals from feldspar-rich sediment extracts. Radiat. Meas. 43, 1474-1486.

Turney, C.S.M., Bird, M.I., Fifield, L.K., Roberts, R.G., Smith, M.A., Dortch, C.E., Grün, R., Lawson, E., Ayliffe, L.K., Miller, G.H., Dortch, J., Cresswell, R.G., 2001. Early human occupation at Devil's Lair, south-western Australia 50000 years ago. Quat. Res. 55, 3-13.

Wintle, A.G., 1973. Anomalous fading of thermoluminescence in mineral samples. Nature 245, 143-144.

Wintle, A.G., 2008. Fifty years of luminescence dating. Archaeometry 50, 276-312.

Wood, R.E., Douka, K., Boscato, P., Haesaerts, P., Sinitsyn, A., Higham, T.F.G., 2012 Testing the ABOx-SC method: dating known-age charcoals associated with the Campanian Ignimbrite. Quat. Geochronol. 9, 16-26.

Wood, R.E., Barroso-Ruíz, C., Caparrós, M., Jordá Pardo, J.F., Santos, B.G. Higham, T.F.G., 2013. Radiocarbon dating casts doubt on the late chronology of the Middle to Upper Palaeolithic transition in southern Iberia. Proc. Natl. Acad. Sci. U. S. A. 110, 2781-2786.

Zhao, H., Li, S.H., 2002. Luminescence isochron dating: a new approach using different grain sizes. Radiat. Prot. Dosim. 101, 333-338. 